\title{
FRÜHAWARENZEITLICHE BESTATTUNGSSITTEN IM GEBIET DER GROSSEN UNGARISCHEN TIEFEBENE ÖSTLICH DER THEISS. ARCHÄOLOGISCHE ANGABEN UND BEMERKUNGEN ZUR GESCHICHTE DER REGION IM 6. UND 7. JAHRHUNDERT
}

\author{
GÁBOR LŐRINCZY \\ lorinczyg@gmail.com
}

\begin{abstract}
The study discusses and presents the archaeological phenomena of burial practices observed in the graves of the Early Avar Age cemetery of Szegvár-Oromdülő. Besides orientation, these are the three types of differently formed graves, the stumped variant of fractional animal burials, the spatial separation of the deceased and the accompanying animal remains, and the custom of interring pottery and bone-in meat (lamb rump bone) into graves. It analyses these important but so far not thoroughly exploited groups of sources in regard of the $6^{\text {th }}-7^{\text {th }}$ century burials of a larger geographical unit, the Trans-Tisa (Tiszántúl) region, since the population of this region can be better characterized by their funerary practices than their tangible cultural heritage. In addition, it refers to the presence or absence of these characteristics in the burials of a smaller area within the investigated region - the territory bordered by the Körös, Tisza and Maros Rivers - dating to the second half of the Avar Age, and through this, to their continuity.

It delineates the grave goods of female and male burials which represent the inheritance of the first generation among the graves of the Trans-Tisa region. Their common feature is their different provenance. Thus there are grave goods with Eastern European, steppe connections, grave goods of Byzantine taste or origin, as well as grave goods of local, Gepidic provenance among them.

Communities of the Trans-Tisa region in the $6^{\text {th }}-7^{\text {th }}$ century Carpathian Basin are characterized by a chain of significant archaeological phenomena of burial customs exclusively attributed to them, which were commonly spread within a certain area and continuously practiced for generations. Based on these features, the population that settled here can be well outlined in respect of origin, traditions and cultural affiliation.

In the author's opinion it can be presumed by the sparse reports of Byzantine sources that this region was occupied and inhabited by a population referred to as Kutrigurs by contemporary sources and steppe people led by them.

Keywords: burial practices, Early Avar Age, first generation, Szegvár, Trans-Tisa region, Kutrigurs
\end{abstract}

\section{EINLEITUNG}

Östlich des Ortsgebietes von Szegvár im Komitat Csongrád (Abb. 1.1) zieht sich ein Sandrücken hin. Er ragt 3-4 Meter aus seiner Umgebung heraus und war ursprünglich etwa 2000 Meter lang und 100 Meter breit (Abb. 1.2). Die örtliche landwirtschaftliche Produktionsgenossenschaft benutzte den mittleren Abschnitt des Hügelzugs in den Jahren von 1980 bis 1997 zur Sandförderung. In diesen 18 Jahren, dem Jahr für Jahr geplanten Sandabbau vorangehend wurden die dadurch betroffenen Bereiche archäologisch untersucht. Im Laufe der Grabungskampagnen konnten auf einer Fläche von etwa $36000 \mathrm{~m}^{2}$ Teile einer Siedlung aus der römischen Kaiserzeit, ${ }^{1}$ eines sarmatischen Gräberfeldes und von zwei weiteren Bestattungsplätzen, die den 6. und 7. Jahrhunderten ${ }^{2}$ bzw. den 10. und 11. Jahrhunderten ${ }^{3}$ angehören, freigelegt werden (Abb. 1.3).

${ }^{1}$ ISTVÁNOVITS-LÖRINCZY-PINTYE 2005.

${ }^{2}$ LŐRINCZY 1992a; LŐRINCZY 1995.

\footnotetext{
${ }^{3}$ BENDE-LŐRINCZY 1997.
} 

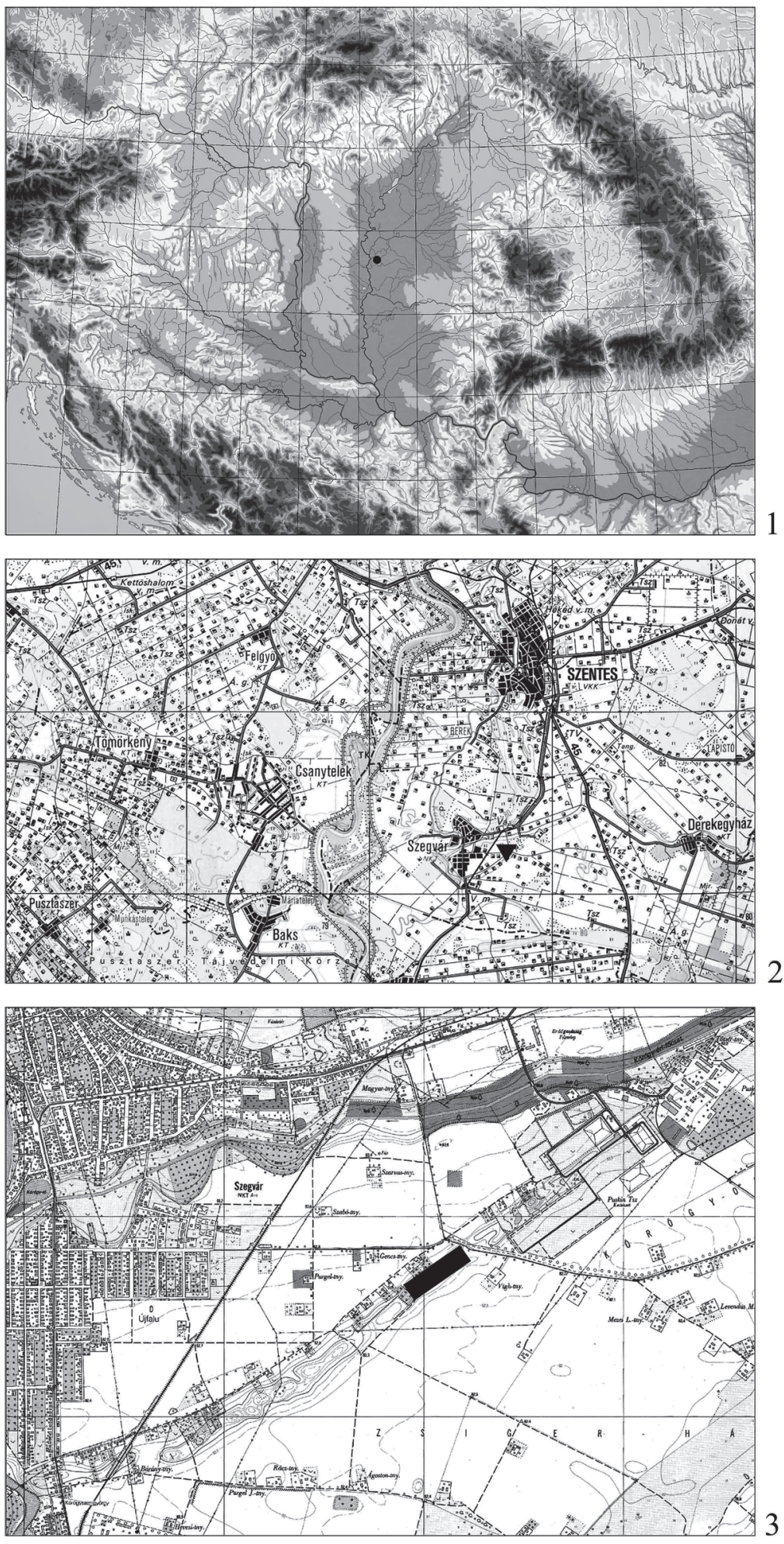

Abb. 1. 1: Die Lage von Szegvár im Karpatenbecken; 2: Die weitere Umgebung des Fundortes; 3: Das freigelegte Gebiet mit seiner unmittelbaren Umgebung 
Die frühawarenzeitlichen Gräber (6.-7. Jahrhundert) lagen auf dem Rücken des NO-SW gerichteten Hügelzugs, an seinem Nordwesthang und an seinem Fuß. Der bis 1997 bekannt gewordene Gräberfeldteil umfasst eine Fläche von ca. $21000 \mathrm{~m}^{2}$. Nur in Richtung Südosten kann das Gräberfeld als gänzlich erforscht betrachtet werden, weil auf dem Rücken des Hügelzugs auf die äußersten Gräber eine große Fläche ohne Bestattungen folgt. Der Nordostrand des Gräberfeldes wurde durch die Sandförderung vernichtet. Der am Hügelfuß vermutete nordwestliche ${ }^{4}$ und der südwestliche Rand auf dem Hügelrücken wurden durch die Grabung nicht erreicht.

Bei der Bewertung des frühawarenzeitlichen Gräberfeldes stellt eine große Hilfe dar, dass in seinem bekannt gewordenen Teil lediglich 27 Gräber $-6 \%$ aller freigelegten Gräber - alt geplündert waren.

\section{ÜBER DIE ORIENTIERUNG DER GRÄBER}

Für die überwiegende Mehrheit der Gräber ist die NO-SW-Orientierung bezeichnend, bei der der Kopf der Verstorbenen im Nordosten niedergelegt wurde. Diese Orientierung befindet sich im Bereich $37-53^{\circ}$. Die Abweichung in Nordrichtung beträgt 3-4 $4^{\circ}$, dagegen in Südrichtung $23-33^{\circ}$. Aufgrund dessen war bei einem Teil der Gräber ONO-WSW typisch. ${ }^{5}$ Bei der Analyse der Orientierung muss berücksichtigt werden, dass es sich einerseits um die Bestattungen von Kindern und Erwachsenen, um Schacht-, Nischen- und Stollengräber, andererseits um Bestattungen handelt, die in der gesamten Belegungszeit des Gräberfeldes datierbar sind und auf dem Rücken und an der Seite bzw. am Fuß des Hügelzugs gefunden wurden.

An den letzteren Gesichtspunkt schließt sich die - heute nicht mehr eindeutig zu entscheidende - Frage an, wie sehr die Orientierung der Gräber von der ONO-WSW-Richtung des Sandhügelzugs beeinflusst wurde, der von der Ur-Körös geschaffen und vom hier herrschenden Nordwestwind zusammengetragen worden war und auf dessen Rücken und seiner Nordwestseite die Gräber lagen.

Für die entscheidende Mehrheit der aus der weiteren Umgebung des Gräberfeldes von Szegvár-Oromdűlő bzw. dem Gebiet jenseits der Thei $B^{6}(A b b .2)$ bekannten frühawarenzeitlichen Bestattungen ist die O-W- bzw. NOSW-Orientierung typisch. ${ }^{7}$ Aus dem Arbeitsgebiet liegen heute schon mehr oder weniger Informationen von über zweihundert, in die Frühawarenzeit datierbaren Funden/Fundorten vor. ${ }^{8}$ Ein bedeutender Teil von ihnen sind im 19. Jahrhundert gefundene und ohne andere Angaben als die Benennung des Fundortes in Museumssammlungen gekommene Streufunde und in anderen Fällen mangelhafte Fundensembles. Ihr anderer Teil wurde zwar in der zweiten Hälfte des 19. Jahrhunderts bzw. den ersten Jahrzehnten des 20. Jahrhunderts freigelegt, die Orientierungsangaben sind aber auch in ihrem Fall nicht aufgezeichnet. So ist es kein Zufall, dass es von der Mehrheit, von fast 125 Fundorten, keine Information über die Orientierung der Gräber gibt. Bei mehr als der Hälfte der Gräber/Fundorte mit Orientierungsangabe, bei den Bestattungen von etwa 60 Fundorten, stimmt die Orientierungsrichtung mit der im Gräberfeld von Szegvár-Oromdűlő beobachteten NO-SW- bzw. O-W-Orientierung überein, was die Richtung der frühawarenzeitlichen Bestattungen determinierend charakterisiert. ${ }^{9}$ Die übrigen Bestattungen verteilen sich zu je einem Drittel auf die Orientierungs-Hauptrichtungen NW-SO, N-S und W-O. ${ }^{10}$

${ }^{4}$ Im Nordwesten, außerhalb des am Fuß des Hügelzuges freigelegten Grabens - der lange Zeit für den Gräberfeldgraben gehalten und als solcher bestimmt wurde -, fanden sich bei der Fortsetzung der Grabung erneut Gräber.

${ }^{5}$ Anzumerken ist, dass $3 \%$ der Gräber im Gräberfeld, d. h. 15 Bestattungen, umgekehrte, SW-NO-Orientierung haben.

${ }^{6}$ Hier und im Weiteren ist unter dem Gebiet östlich der Theiß das Territorium der östlichen Hälfte des Karpatenbeckens östlich der Theiß zu verstehen, das sich im Norden bis zum Theißbogen, im Osten bis zum östlichen Fuß des Siebenbürgischen Mittelgebirges und im Süden bis zum Arankatal erstreckt.

${ }^{7}$ Während vor 25 Jahren die obige Richtung der Orientierung der Gräber nur an 31 Fundorten der ca. 150 bekannten frühawarischen Fundorte aus dem Gebiet maßgeblich war (LŐRINCZY 1992b, 164-165), ist nach den seitherigen Zusammenfassungen für die Grä- ber von fast 50 Fundorten diese Orientierungsrichtung typisch (LŐRINCZY 1995, 403; LŐRINCZY 1996, 178-179).

${ }^{8}$ Abgesehen von den Streufunden gibt es im Gebiet östlich der Theiß keinen Gräberfeldteil, der in der Frühawarenzeit benutzt wurde und eine Fortsetzung gehabt hätte, die in die zweite Hälfte des 7. Jahrhunderts oder die ihr folgende Periode datiert werden könnte.

${ }^{9} \mathrm{Zu}$ diesen sind auch vier SO-NW orientierte Bestattungen zu zählen, deren Bestattungssitten identisch mit denen sind, die in den NO orientierten Gräbern beobachtet wurden.

${ }^{10}$ Anzumerken ist: Bei der Bewertung muss beachtet werden, dass in vielen Fällen bei der Angabe der Orientierungsrichtung kein Kompass benutzt wurde und diese Angaben somit teilweise die Möglichkeit der Ungenauigkeit enthalten, da der Richtungsangabe der Zahlenwert fehlt. 
Die Orientierung der Gräber des 6.-7. Jahrhunderts im Karpatenbecken ist sehr variabel, worauf schon mehrere Forscher hingewiesen haben. ${ }^{11}$ Während die entscheidende Mehrheit der Gemeinschaften östlich der Theiß ihre Gräber in der NO-Richtung orientierten, war in derselben Periode im westlich der Theiß gelegenen Teil des Karpatenbeckens, im Gebiet zwischen Donau und Theiß und in Transdanubien, bekanntermaßen die W-O-Orientierung üblich.

Im Arbeitsgebiet ist eine wichtige Angabe zur Geschichte des 7.-8. Jahrhunderts, dass in einer geographisch gut umreißbaren Landschaftseinheit - im Gebiet zwischen Körös, Theiß und Maros - für die in der zweiten Hälfte der Awarenzeit entstandenen Gräber dagegen die Richtung NW-SO bestimmend war und es bisher kein Beispiel der für die Frühawarenzeit typischen NO-SW-Orientierung gibt. Das ist ein Hinweis darauf, dass in den Gräberfeldern, die von der in dem Gebiet weiterlebenden frühawarenzeitlichen Bevölkerung geöffnet wurden, die Orientierung nicht zu den konservativ bewahrten Bestattungstraditionen gehörte. ${ }^{12}$

Um auf das Gräberfeld von Szegvár zurückzukommen, waren von den bis zum Ende der Rettungsgrabungen 1997 freigelegten annähernd 500 Gräbern etwa 260 Schacht-, 90 Nischen- und 150 Stollengräber. In den drei unterschiedlichen Grabformen waren gleicherweise Kinder und Erwachsene, Frauen und Männer bestattet worden.

\section{ÜBER DIE VERSCHIEDENEN GRABFORMEN}

\section{Das Schachtgrab}

Die Schachtgräber des Gräberfeldes von Szegvár stimmen einerseits mit der allgemeinen Form der völkerwanderungszeitlichen Gräber überein, d. h. die Wände des rechteckigen Grabes mit abgerundeten oder nur leicht abgerundeten Enden waren fast senkrecht, ihre Sohle gerade oder schwach muldenförmig. Aber es gibt eine Form, die man als Grab mit Seitenrillen bezeichnen kann. Bei diesem Grabtyp wurde in den beiden Längsseiten des Grabes je eine ca. 10-15 cm tiefe und 15-20 cm hohe, von der Grabsohle 55-60 cm entfernte Horizontalrille angelegt (Abb. 3.3). Ihre Funktion stimmte mit den Stufen der zweiseitigen Stufengräber überein, d. h. sie hielten das quer über die Toten oder deren Särge gelegte Holz (Zweige, Bretter). Während der Bestattung wurden darauf die Überreste der abgehäuteten Tiere gelegt, der in der Haut belassene Schädel und die Beinknochen. Die Zahl der bisher publizierten Schachtgräber $(1,65,704 \text { und } 881)^{13}$ wird hier durch ein neues erweitert.

Grab 132 (Abb. 3.1-3; Abb. 7.1). Grab mit Seitenrillen. O: NO-SW, 46-226․ L: $210 \mathrm{~cm}, \mathrm{~B}: 85-90 \mathrm{~cm}$, T: $90 \mathrm{~cm}$. Das nordöstliche Drittel des rechteckigen Grabes mit abgerundeten Ecken erschien als graubrauner, ${ }^{14}$ dagegen das südwestliche Drittel als grellgelber Fleck. 15-20 cm unter der abgetragenen Oberfläche war in beiden Längsseiten des Grabes je eine 15-18 cm hohe und $15 \mathrm{~cm}$ tiefe Höhlung geschaffen worden. In der oberen Schicht - auf die quer in die Höhlung in den Seitenwänden gelegten Hölzer - hatte man den partiellen Überrest dreier Rinder und eines Schafes (Schädel und die am distalen Ende der Tibiae und Radien abgehacken Fußknochen) abgelegt. Auf der 3-6 cm dicken Auffüllung über dem muldenförmigen Boden wurde der Skelettrest einer Frau im adulten Alter (35-39-jährig) in gestreckter Rückenlage gefunden. Ihr deformierter Schädel lag auf der linken Seite. Die linken Brustkorbrippen und die linken Ober- und Unterarmknochen fehlten infolge der Grabberaubung. Die rechtsseitigen und vom Becken abwärts befindlichen Skelettteile lagen in anatomischer Ordnung.

Tierbeigaben. 1. Schädel einer juvenilen (11/2-2-jährigen) Kuh auf dem Kiefer liegend, zur Grabmitte hin kippend, mit der Nase nach Osten oberhalb des linken Oberarmes der Frau, die Vorderbeinknochen unter dem Kuhschädel, die Hinterbeinknochen unter dem Bullenschädel, die Schwanzwirbel lagen beim Aufnehmen unter den Kuhschädeln. 2. Schädel einer adulten Kuh auf der linken Seite, in Richtung Grabmitte kippend hinter dem Kuhschädel, mit der Nase in nordöstlicher Richtung neben der Südostwand des Grabes, die Vorderbeinknochen am Südostende des Grabes, die Hinterbeinknochen und Schwanzwirbel am südwestlichen Ende. 3. Schädel und Beinknochen eines Rinderfötus in der Südostecke des Grabes, unter den Kuhbeinknochen. 4. Schädel eines infanten

\footnotetext{
${ }^{11}$ Beispielsweise Kovrig 1963, 91; ToMKa 1975, 5-9; BÓNA 1986, 78; TOMKA 2008, 242.

${ }^{12}$ BENDE 2006, 88.
}

${ }^{13}$ LÖRINCZY 1992a， 81-90; LŐRINCZY 1998，350; LÖRINCZY-STRAUB 2004, 315-317; LÖRINCZY-STRAUb 2005, 127. der Raubgrube. 


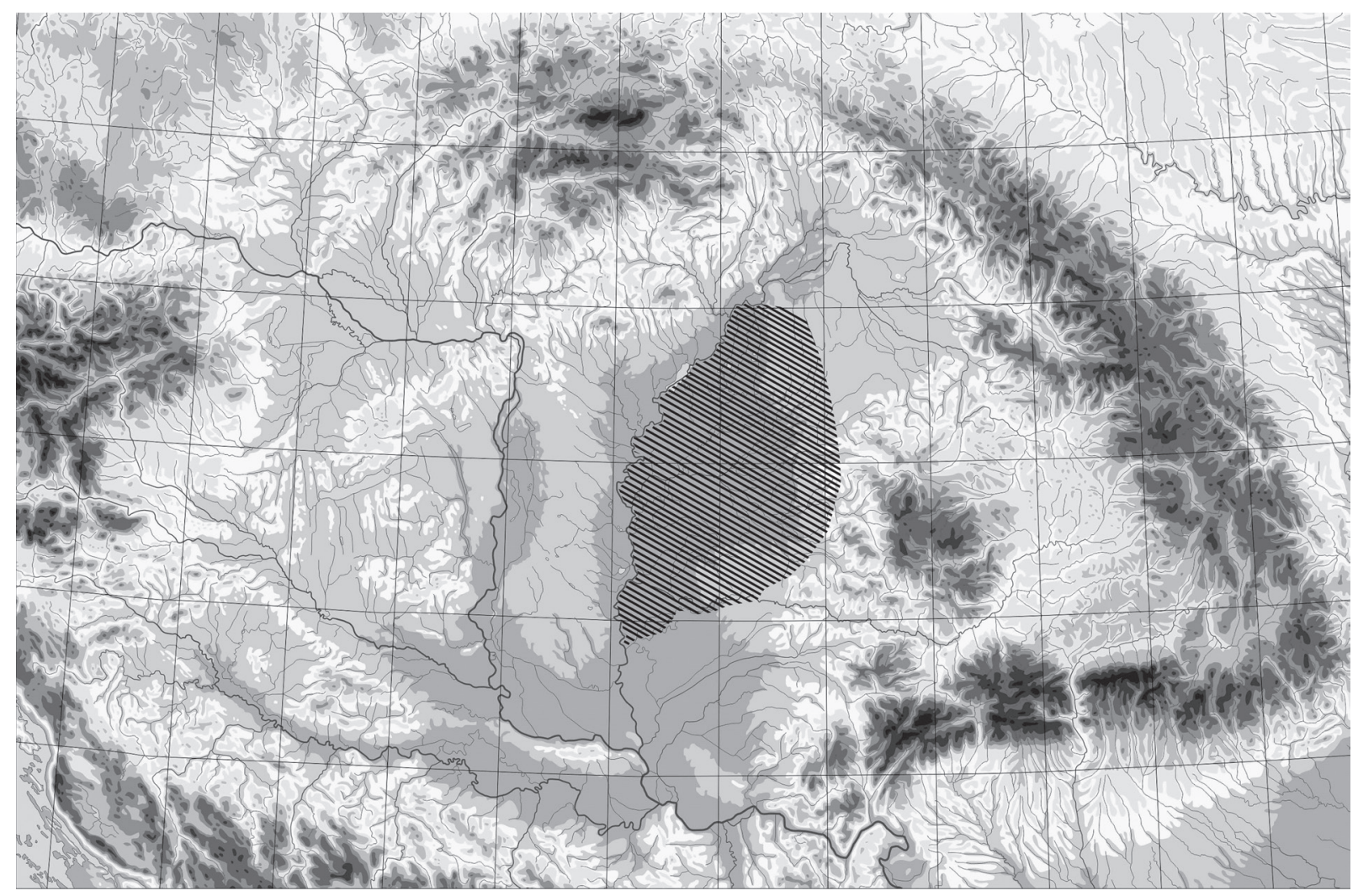

Abb. 2. Das Arbeitsgebiet innerhalb des Karpatenbeckens

(6-8-monatigen) hörnerlosen Widders auf die rechte Seite gewendet, mit der Nase in Nordostrichtung, seine Beinknochen neben und unter den Beinknochen der neben der südöstlichen und südwestlichen Wand liegenden Kuh.

Die Funde des menschlichen Skelettes. 5. Fragment vom Kreuzbein und der sechste Lendenwirbel eines subadulten Schafes an der Stelle der Halswirbel, in einem Tiergang, in sekundärer Lange. 6. Spinnwirtel aus dem Wandfragment eines außen roten, innen grauen, großen scheibengedrehten Gefäßes (Abb. 3.8) zwischen den rechten Unterarmknochen, auf seiner Kante stehend, in Querlage zur Grabachse. Dm: 4,5 cm, D: 1,1 cm.

Trachtgegenstände. Zwei Perlen kamen bei der Freilegung aus der Füllerde zum Vorschein. 7. Weiße, abgegriffene, löchrige, matte, deformierte, kurze zylindrische opake Glasperle ( $A b b$. 3.5) mit zylindrischer Bohrung. L: 0,58-0,7 cm, Dm: 0,7 cm, Bohrungs-Dm: 0,3 cm. ID.No.: 1190. 8. Dunkelblaue, stark abgegriffene, deformierte, lange viereckig säulenförmige, durchscheinende Glasperle mit abgeschnittenen Ecken ( $A b b$. 3.4) und konischer Bohrung. L: 0,6-0,7 cm, Dm: 0,55 cm, Bohrungs-Dm: 0,15-0,2 cm. ID. No.: 1191. 9. Eisenschnalle (Abb. 3.6) im Bereich zwischen rechten Handknochen und Beckenschaufel, der Dorn zeigte nach oben und in Richtung Schädel. Den größeren Teil ihrer Fläche bedeckt durch Eisenoxyd konserviertes Leder. L: 3,7 cm, B: 3,4 cm.

Hier ist zu erwähnen, dass von den bis 1991 bekannt gewordenen Bestattungen 42 Schachtgräber als Kenotaph bestimmt wurden, also weder menschliche und tierische Überreste noch archäologische Funde enthielten. ${ }^{15}$ Die Zugehörigkeit der bei der Fortsetzung der Freilegung gefundenen neuen, mit den bisherigen leeren Objekten und den frühawarenzeitlichen Gräbern gleicherweise übereinstimmenden, NO-SW orientierten, ähnlich aufgefüllten und zusammengesetzten, auf dem Hügelrücken in einer Reihe liegenden Objekte zu den awarischen Gräbern schien eindeutig zu sein. Bei der Ausgrabung 1997 am Südwestrand des freigelegten Gebietes fanden sich auf dem Hügelrücken zwei Verfärbungen in Superposition. In einer Reihe mit den NO-SW gerichteten, schon erwähnten, in einer Linie liegenden Objekten wurde Objekt 958 gefunden, das vom S-N orientierten sarmatischen Grab 955 ge-

\footnotetext{
${ }^{15}$ LŐRINCZY 1992a, 81.
} 

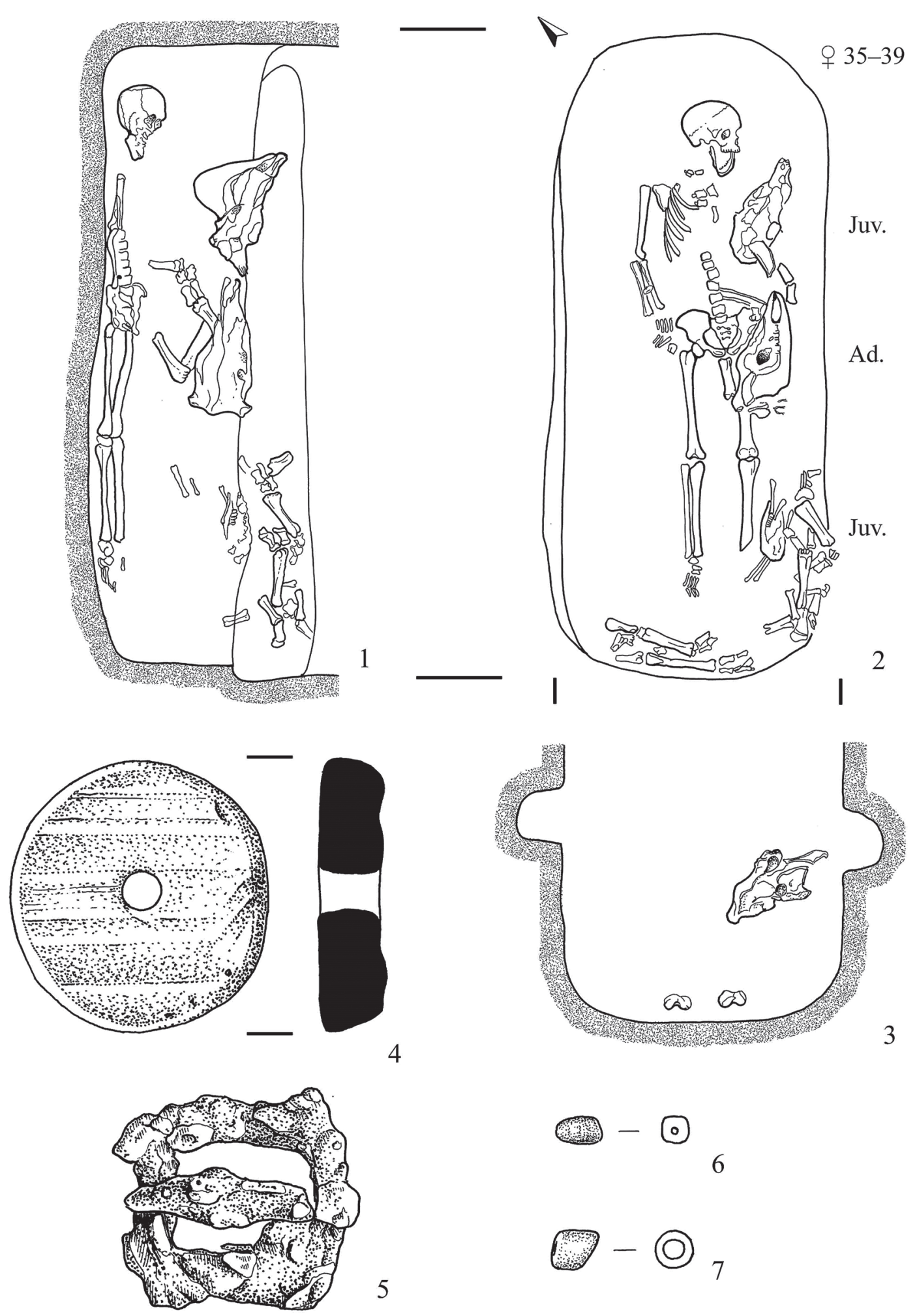

4

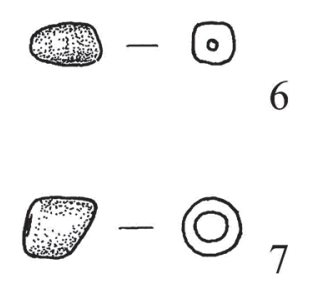

Abb. 3. Szegvár-Oromdűlő Grab 132 
schnitten wurde. Aufgrund dessen kann man annehmen, dass es mehr als zweifelhaft ist, die leeren Objekte als Kenotaphe zu deuten und in die Awarenzeit einzureihen.

\section{Das Nischengrab}

Etwa ein Fünftel, fast 90, der im Gräberfeld von Szegvár-Oromdülő freigelegten Gräber waren Nischengräber (grave with a sidewall niche), von denen Grab 126, 130 und 915 bereits veröffentlicht sind. ${ }^{16}$ Die allgemeinen Beobachtungen an den Nischengräbern von Szegvár werden im Folgenden zusammengefasst.

Anders als das allgemeine Schachtgrab ist das Nischengrab eine Grabgrube zusammengesetzter Konstruktion, bei der in die nordwestliche Längsseite des Schachtes eine Höhlung, eine so genannte Nische, eingetieft wurde. So überstieg die Länge der Grabgrube die Länge des traditionellen Schachtgrabes höchstens geringfügig. Zu ihrer Breite kommt jedoch auch die Breite der Nische hinzu, sie kann also eventuell auch fast $2 \mathrm{~m}$ erreichen.

Der Fleck des Schachtes oder der Vorraumgrube des Nischengrabes zeigt sich auf unterschiedliche Weise im sandigen/lehmigen gewachsenen Boden. Häufig war er einheitlich, gleichartig, in der Art etwas dunkler als der gewachsene Boden. Bei der Aushöhlung der tieferen großen Nische wurde jedoch sehr viel Sand/Lehm aus dem gewachsenen Boden gefördert. Da der Nischeneingang immer abgesperrt wurde, hat man die Höhlung nicht aufgefüllt. In den Schacht legte man die vollständigen oder partiellen Überreste von Pferden oder Widerkäuern. Die gleichartige, nicht gemischte Menge des ausgehobenen gewachsenen Bodens kam beim Zuschütten des Grabes in die obere Schicht des Schachtes. In diesem Fall hat sich bei der Freilegung die helle Grabfüllung auf dem Niveau des Planums oftmals nicht markant vom ungestörten gewachsenen Boden unterschieden, sie stimmte in vielen Fällen fast völlig mit ihm überein. Die Beobachtung auf dem abgeräumten Niveau wurde weiter dadurch erschwert, dass sich dem regelmäßig rechteckigen Schachtfleck an einer seiner Längsseiten, über der Nische, oft ein relativ unregelmäßiger ovaler Fleck mit unsicheren Konturen anschloss. Denn beim Einstürzen/Absinken der Nischendecke sackte die Masse dunkleren Materials des Naturbodens in den helleren gewachsenen Boden. Häufig war die Kontur der beim Absacken entstehenden Verfärbung ungeachtet allen Verwaschenseins dunkler, besser zu erkennen als der gleichartige, mit dem gewachsenen Boden fast gleichfarbige Fleck des Schachtes. Deshalb konnte es bei früheren Ausgrabungen geschehen, dass der Grabgrubenschacht und der Nischenteil verwechselt wurden und nicht der Schachtteil des Grabes, sondern die Nische zuerst untersucht wurde. Die „Verfärbung“ der Nische ist aber in größerer Tiefe nicht mehr zu erkennen, denn die Nische wurde nicht von der Oberfläche aus eingetieft, über ihr war der gewachsene Boden immer ungestört.

Der Vorraum/Schacht des Nischengrabes war meist groß, mit abgerundeten Ecken, länglich rechteckig. Er ähnelte den Schachtgräbern. Die Seitenwände des Schachtes waren annähernd senkrecht oder leicht nach unten verengt. Die Sohle war allgemein waagerecht, der Streifen vor der Nische dagegen abschüssig, sehr selten mit Stufen gestaltet.

Die Trennung des Schachtes von der Nische geschah auf unterschiedliche Weise. Bei allen Nischengräbern ist - unabhängig davon, ob dies beobachtet werden konnte - damit zu rechnen, dass die Nische mit Leder, Holz oder anderem organischem Material geschlossen wurde. Unmittelbar vor dem Eingang war im Schacht oft eine dunklere Füllungserde als die des Schachtes zu beobachten, oftmals schwarz mit braunen Pünktchen und fettig anzufühlen. Sie verweist vermutlich auf das zusammengerollte Tierfell hin, mit dem der Eingang zur Seitennische versperrt worden war.

Die Nische selbst wurde in einer der Längsseiten des Schachtes ausgehöhlt. Ihr Boden war selten mit dem Schacht gleich tief, häufig war tiefer als er. Die Länge der Seitennische war oft größer als die des Schachtes, ihre beiden Enden und die Längsseite waren gebogen und ihre Decke gewölbt. Die Nische war in Relation zum Schacht immer groß. Im Schacht wurden die Tierbeigaben untergebracht.

Aus der Wölbung der Nische brachen im Laufe der Zeit kleinere bis größere Stücke heraus und die aus dem Schacht von Zeit zu Zeit ausgeschwemmte Erde mochte Schichten in der Grabfüllung gebildet haben. Die bei

${ }^{16}$ LŐRINCZY 1992a, 103, Abb. 17-18; LŐRINCZY-STRAUB

2004, 306-307, 317. 
der Aufdeckung im Schnitt zu sehende Wölbung ist wegen des Abbrechens immer als sekundär zu betrachten, die ursprüngliche Höhe kann also immer etwas größer als die zu erkennende gewesen sein.

Zur Illustration dessen wird hier ein weiteres Nischengrab dargestellt.

Grab 187 (Abb. 4.1; Abb. 7.2). Nischengrab. O: NO-SW, 50-230'. Schacht-L: $250 \mathrm{~cm},-B: 80-90 \mathrm{~cm},-\mathrm{T}$ : 42-68 cm. Der bräunlich graue Fleck des Schachtes zeichnete sich mit klarem Umriss im gelblich braunen gewachsenen Boden ab. Dem Schachtfleck schloss sich auf seiner nordwestlichen Seite ein ovaler grauschwarzer Fleck mit unsicherem Umriss an. Der Schachtboden war an der Südostwand $20 \mathrm{~cm}$ lang waagerecht und fiel dann zum Nischeneingang hin ab. Im Schacht lagen die partiellen Überreste von vier Rindern und sieben Schafen (Schädel und die am distalen Ende der Tibiae und Radien abgehacken Fußknochen) sowie drei Lämmern in 5-25 cm dicker Auffüllung. Im Nischeneingang war die Füllerde $25-30 \mathrm{~cm}$ dick in voller Schachtlänge und $35-40 \mathrm{~cm}$ breit schwarz und fettig anzufühlen. Nischen-L: $250 \mathrm{~cm}$, -B: $80-85 \mathrm{~cm}$, -T: $75 \mathrm{~cm}$. In der Nische mit leicht muldenförmigem Boden lag der Skelettrest einer maturen Frau (44-50 J.) in gestreckter Rückenlage in einer 3-8 cm dicken Auffüllung. Aufgrund der Verfärbung der Füllerde war die erwachsene Frau in einem an beiden Enden halbrunden, 190 $\mathrm{cm}$ langen und $52 \mathrm{~cm}$ breiten Sarg bestattet worden. Der Umriss des Sarges konnte $11 \mathrm{~cm}$ über der Grabsohle beobachtet werden. Der Schädel der Frau lag leicht nach rechts gewendet nach hinten gesunken, ihren Kiefer hatte ein Nagetier zwischen linkes Schlüsselbein und Oberarm verschoben. Der ganze Brustkorb war von Tiergängen gestört, zum Beispiel befanden sich zwischen Schulter und Schädel Fingerknochen. Die Knochen beider Unterarme waren verschoben. Die Beinknochen lagen parallel nebeneinander.

Tierbeigaben und ihre Funde. 1. Schädel eines maturen Bullen (8-10 J.) auf dem Kiefer liegend am Nordwestende des Schachtes, mit der Nase in Nordostrichtung, Vorderbeinknochen in der Mitte des Schachtes, Hinterbeine und in anatomischer Ordnung liegende Schwanzwirbel am Südwestende des Schachtes. 2. Unbestimmbare Silberbeschlagfragmente (Abb. 4.5) auf einer handflächengroßen Fläche des Bullenschädels. 3. Schädel einer maturen Kuh (10-12 J.) auf dem Kiefer liegend in der Nordosthälfte des Schachtes, neben der südöstlichen Grabwand, mit der Nase Richtung Nordosten, Beinknochen und in anatomischer Ordnung liegende Schwanzwirbel am südwestlichen Ende des Schachtes. 4. Schädel eines infanten Rindes (6-8 M.) auf dem Kiefer liegend in der Schachtmitte, neben der südöstlichen Grabwand, mit der Nase Richtung Nordosten, Beinknochen und Schwanzwirbel am Südwestende des Schachtes. 5. Schädel einer juvenilen Kuh (1 1/2-2 J.) auf dem Kiefer liegend in der Südwesthälfte des Schachtes, neben der südöstlichen Grabwand, mit der Nase Richtung Nordosten, Beinknochen und Schwanzwirbel hinter dem Schädel, am Südwestende des Schachtes. 6. Schädel einer juvenilen hornlosen Ziege (ca. 2 J.) auf der linken Seite liegend neben dem Bullenschädel, mit der Nase Richtung Nordosten, Beinknochen über bzw. hinter den Schädeln der adulten Schafe, in der Südwesthälfte des Schachtes. 7. Schädel eines adulten hornlosen Widders auf der rechten Seite liegend in der Mitte des Schachtes, mit der Nase Richtung Osten, Beinknochen am Südwestende des Schachtes. 8. Schädel eines adult-maturen hornlosen Schafes auf der linken Seite liegend in der Mitte des Schachtes, mit der Nase Richtung Norden, Beinknochen am Südwestende des Schachtes. 9. Schädel eines juvenilen (1-1/1/4 J.) hornlosen Schafes auf der linken Seite liegend unter dem Schädel der juvenilen Kuh bzw. zwischen dem Schädel und der südöstlichen Grabwand, mit der Nase Richtung Norden, Beinknochen am Südwestende des Schachtes. 10. Schädel und Beinknochen eines adulten Schafes am Südwestende des Schachtes, unter den Kuhund Schafbeinknochen. 11. Fötus (Embryo) eines Schafes (Lammes) in zerstückeltem Zustand in der Schachtmitte, beim Schädel der maturen Kuh. Der vom Rumpf getrennte Schädel und die vier Beine sowie die Wirbel lagen in anatomischer Ordnung, d. h. bei der Bestattung war die Wirbelsäule ganz. 12.-13. Körperteile von zwei Föten (Embryos) von Schafen (Lämmern) am Südwestende des Schachtes, zwischen den Kuh- und Schafbeinknochen. 14. Schädel, Mandibel und einige Langknochen eines juvenilen (1-11/2 J.) Schafes am Südwestende des Schachtes, zwischen den Kuh- und Schafbeinknochen.

Die Funde des menschlichen Skeletts. 15. Schädel eines subadulten Schafes auf dem Schädeldach liegend am Nordostende des Nischeneingangs, mit der Nase Richtung Osten, Beinknochen in der Nordosthälfte des Nischeneingangs, in dessen Streifen. 16. Gelblich graues, grauschwarz fleckiges, handgeformtes Gefäß von gestreckter Form (Abb. 4.11) am Nordostende der Nische, $20 \mathrm{~cm}$ hinter dem Schädel: schwach ausgearbeitetes Material, stark mit Sand und Keramikbruch gemagert, raue Oberfläche, ungleichmäßig bearbeitet, eingedrückt, gerissen. Oberfläche ist schlecht erhalten, mit dünner Tonglasur bedeckt. Der kurze Rand ist schräg, trichterförmig ausgebogen, mit dichten Fingereindrücken verziert. Die Schulter ist kräftig, asymmetrisch. Auf einem Viertel ist die Oberfläche ablaufverziert. An der Sohle verengt es sich, der Boden ist gerade abgeschnitten. H: 15,8 cm, Rand-Dm: 11,1 cm, Boden-Dm: 


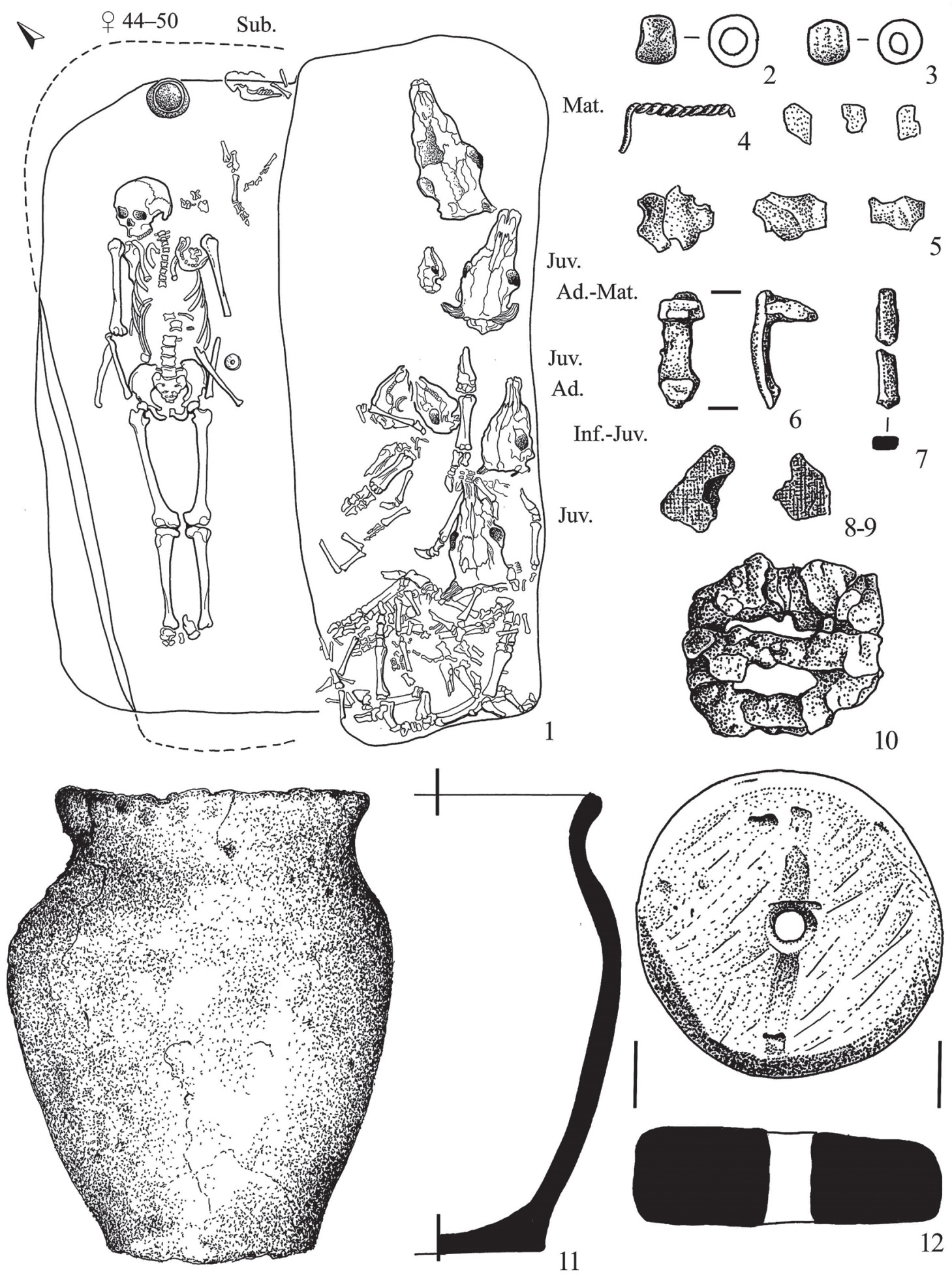

Abb. 4. Szegvár-Oromdülő Grab 187 
$6,9 \mathrm{~cm}$. 17. Lendenwirbel (V.-VI.) vert. lumb., 2 (I.-II.) vert. caud. eines subadulten Widders neben der linken Schädelseite. 18. Spinnwirtel aus dem Wandfragment eines scheibengedrehten grauen Gefäßes (Abb. 2.12), flach an der Stelle der linken Unterarmknochen liegend. Dm: 5,2 cm, D: 1,5 cm, G: 45,47 g. 19. Eisenband in der Form einer Bauklammer (Abb. 4.6), bei der Öffnung der Nische gefunden. Den erhaltenen Haken bedeckt mit Eisenoxyd konserviertes Holz, der andere ist abgebrochen. L: 0,8 cm. 20. Fragmentarischer Eisendraht mit rechteckigem Querschnitt (Abb. 2.7), bei der Öffnung der Nische gefunden. 21. Zwei Bronzeklammern in Bauklammerform aus gedrehtem dünnem Bronzedraht (Abb. 2.4), bei der Öffnung der Nische gefunden. Fragmentarisch. L: $1,9 \mathrm{~cm}$.

Trachtgegenstände. 22. Blaue, deformiert gestaucht kugelförmige, durchscheinende Glasperle (Abb. 4.2) mit zylindrischer Bohrung, ein Rand zerbrochen. L: 0,55-0,65 cm, Dm: 0,82-0,9 cm, Bohrungs-Dm: 0,4 cm. ID. No.: 3334. 23. Hellgrüne, matte, abgenutzte, gestaucht kugelförmige, durchscheinende Glasperle (Abb. 4.3) mit irisierender Oberfläche und zylindrischer Bohrung. L: 0,6 cm, Dm: 0,71-0,8 cm, Bohrungs-Dm: 0,3 cm. ID.No.: 3256. 24. Rechteckige Eisenschnalle (Abb. 4.10) am unteren Ende des Kreuzbeins. Die Oberfläche ist mit durch Eisenoxyd konserviertem Leder bedeckt. Geklebt. L: 3,3 cm, B: 2,8 cm.

Die Angaben und Kenntnisse über die Nischengräber des Karpatenbeckens wurden vor nicht langer Zeit zusammengefasst, wobei neben einem kurzen forschungsgeschichtlichen Überblick, einigen methodologischen und terminologischen Bemerkungen auch ein Fundort- und Grabkatalog veröffentlicht wurde. ${ }^{17}$ Aufgrund der darin enthaltenen und der seit dem Erscheinen der Publikation gefundenen neuen Bestattungen sind heute im Gebiet östlich der Theiß 20 frühawarenzeitliche Fundorte mit einer wechselnden Zahl von Nischengräbern bekannt. ${ }^{18}$ Zugleich muss mit etwas mehr Nischengräbern als bisher bekannt gerechnet werden, weil man auch bis jetzt schon im Fall mehrerer Fundorte - mangels der Dokumentation und der Beobachtung der Grabform - leider nur aufgrund von indirekten Beweisen (der Lage der Tierknochen, höhenmäßiger Unterschiede usw.) Nischengräber vermuten konnte. ${ }^{19}$

Die entscheidende Mehrheit der Nischengräber im Arbeitsgebiet war ebenso gestaltet wie die Nischengräber von Szegvár. Die Nische wurde immer an der Nord-, Nordwestseite des Schachtes geschaffen. Diese Bestattungen verfügen auch über sonstige Eigenheiten: NO-SW-Orientierung, partielle (deformierte) Tierbeigaben. Was diese, im Gebiet östlich der Theiß als allgemein zu betrachtende Grabform betrifft, haben nur zwei Bestattungen andere Merkmale: Hajdúdorog-Városkert u. Grab 1 und Kaba-Belterület. ${ }^{20}$ Deren Erklärung ist aber das Thema einer anderen Studie.

Bezüglich der Verwendung des Nischengrabes muss noch erwähnt werden, dass sich unter den im Gebiet zwischen Körös, Theiß und Maros gefundenen, annähernd 4000 Gräbern aus der zweiten Hälfte der Awarenzeit kein einziges authentisch freigelegtes Nischengrab befindet. ${ }^{21}$ Das gestörte Pferde-/Reitergrab 4 von Örménykút hatte vielleicht Nischenform, doch ist seine Bestimmung unsicher. Wenn Livia Bende Recht mit ihren Bemerkungen zum Grab hat, dann lag in ihm, das als einziges NNW-SSO-gerichtete Nischengrab interpretiert werden kann, das Pferd an der rechten Seite des Mannes, in umgekehrter Orientierung. ${ }^{22}$

Im Sinn all dessen gehörte die Schaffung von Nischengräbern in den Gräberfeldern, die von der in diesem Gebiet weiterlebenden frühawarenzeitlichen Bevölkerung in der zweiten Hälfte der Awarenzeit neu eröffnet wurden, nicht zu den konservativ bewahrten Bestattungstraditionen. Das gilt auch für die Orientierung. Gleichzeitig scheint eine wesentliche Beobachtung zu sein, dass die aus verschiedenen Perioden der Awarenzeit stammenden und aus verschiedenen Regionen des Karpatenbeckens bekannten Nischengräber aufgrund der zur Verfügung stehenden Angaben weder voneinander noch von der frühawarenzeitlichen Grabform im Gebiet östlich der Theiß hergeleitet werden können. ${ }^{23}$

\section{Das Stollengrab}

Im Gräberfeld von Szegvár-Oromdủlő erwies sich ein Drittel der Bestattungen, 150 Gräber, neben den Schacht- und Nischengräbern als Stollengrab (niche dug from the end of the grave pit). Nach den bisher veröffent-

\footnotetext{
${ }^{17}$ LÖRINCZY-STRAUB 2006

${ }^{18}$ In der Mehrheit der Fundorte kam ein einziges Grab vor. Nur bei einigen Gräberfeldern wissen wir von 3-8, in zwei Gräberfeldern von 60-90 gefundenen Nischengräbern.

${ }^{19}$ LŐRINCZY 1996, 181.
}

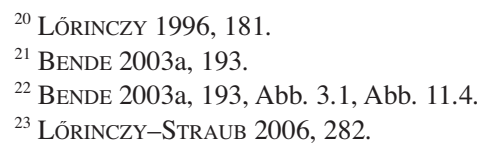




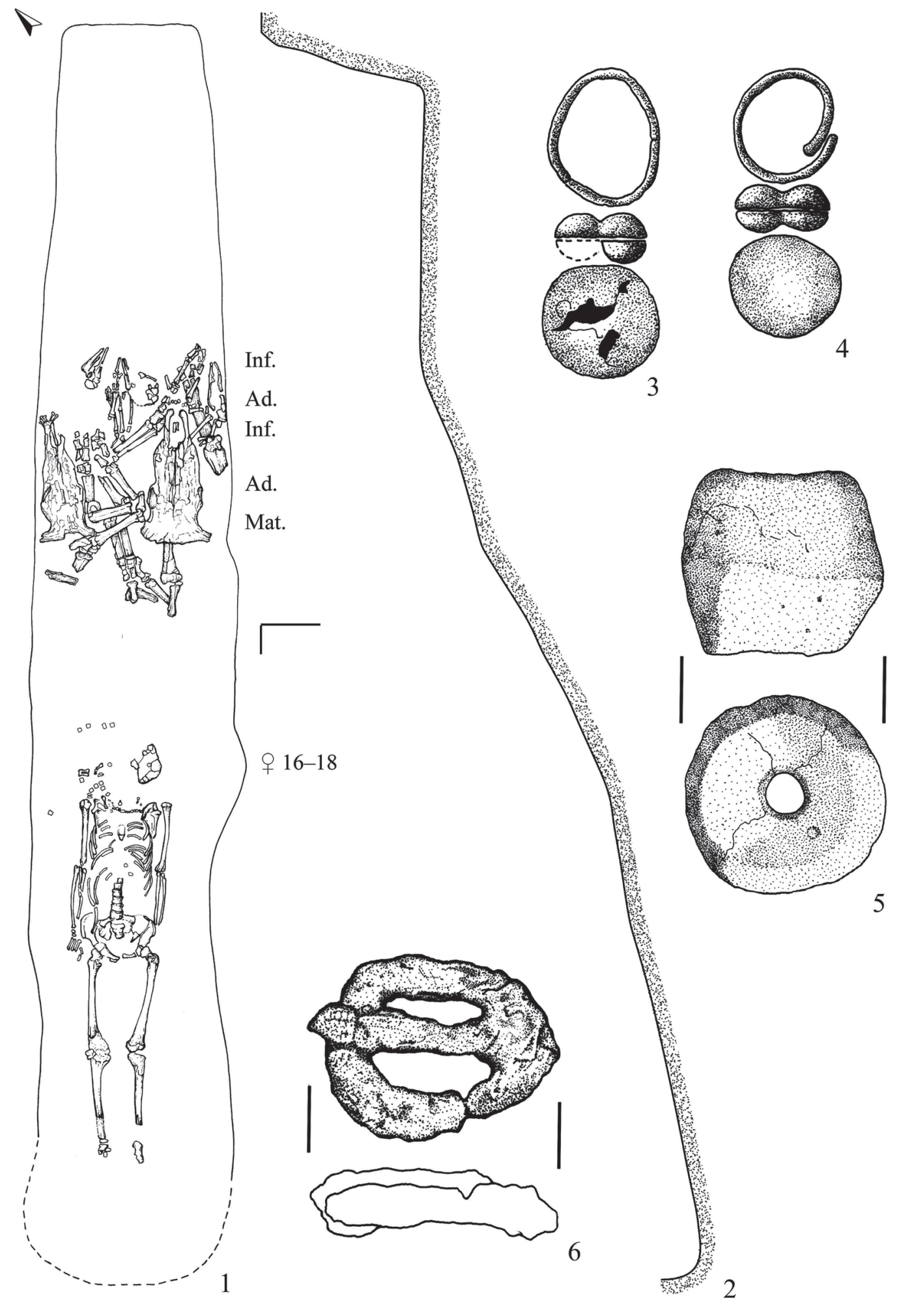

Abb. 5. Szegvár-Oromdülö Grab 761 
lichten Gräbern 1, 98, 100, 109, 134, 196, 554, 692, 753, 829 und $870^{24}$ wird hier ihre Reihe um eine neue Bestattung erweitert.

Grab 761 (Abb. 5.1-2; Abb. 7.3-4). Stollengrab. O: ONO-WSW, 60-240. L: $250 \mathrm{~cm}, \mathrm{~B}: 55-70 \mathrm{~cm}, \mathrm{~T}$ : 50-100 cm. Die nordöstliche Hälfte des rechteckigen Schachtes mit abgerundeten Ecken erschien als grellgelber, die südwestliche Hälfte dagegen als bräunlich grauer Fleck im gelblich braunen, lehmigen gewachsenen Boden. Im Schacht lagen die partiellen Überreste (Schädel und die am distalen Ende der Tibiae und Radien abgehacken Fußknochen) von zwei Rindern und drei Schafen in 2-25 cm dicker Auffüllung. Die nordöstliche Hälfte des Schachtbodens war waagerecht, die südwestliche Hälfte fiel im $25^{\circ}$-Winkel Richtung Stollen ab. Am südwestlichen Ende des Stollens war die Füllerde schwarz. Stollen-L: $260 \mathrm{~cm}$, -B: 70-75 cm, -T: 100-150 cm. Im 10-20ªbschüssigen Stollen lag der Skelettüberrest einer juvenilen Frau (16-18 J.) in gestreckter Rückenlage in 3-4 cm dicker Auffüllung. Der Schädel war zerdrückt, von einem Tiergang etwas gestört, die Schultern waren zusammengezogen, die Armknochen lagen eng neben den Rippen, die Beinknochen parallel nebeneinander. Das der Füllerde des Stollens entnommene Bodenmuster war praktisch pollenfrei.

Tierbeigaben. 1. Schädel einer sechsjährigen Kuh auf dem Kiefer liegend im südwestlichen Viertel des Schachtes, neben der Nordostwand, mit der Nase Richtung Nordosten, Vorder- und Hinterbeinknochen neben und hinter dem Schädel. 2. Schädel eines maturen Bullen auf dem Kiefer liegend im südöstlichen Viertel des Schachtes, neben der Südostwand, mit der Nase Richtung Nordosten, Vorder- und Hinterbeinknochen, Schwanzwirbel neben und hinter dem Schädel, am Südwestende des Schachtes. 3. Schädel eines infanten Schafes (6-8 M.) auf dem Kiefer liegend im südwestlichen Drittel des Schachtes, in der Mitte, mit der Nase Richtung Nordosten, Vorder- und Hinterbeinknochen unter dem Kuhschädel und den Beinknochen. 4. Schädel einer adulten Kuh auf dem Kiefer liegend im südöstlichen Viertel des Schachtes, neben der Südostwand, mit der Nase in Richtung Nordosten, Vorderund Hinterbeinknochen unter dem Bullenschädel und den Beinknochen. 5. Schädel eines infanten Schafes (6-8 M.) auf der rechten Seite liegend im südwestlichen Drittel des Schachtes, nahe der Nordwestwand, mit der Nase Richtung Osten, Vorder- und Hinterbeinknochen unter dem Rinderschädel und den Beinknochen.

Funde des menschlichen Skeletts. 6. Drei Schwanzwirbel vom Schaf hinter der rechten Schulter. 7. Graubrauner doppelkonischer Spinnwirtel (Abb. 5.5) auf der Seite liegend, außen am oberen Drittel des rechten Oberschenkelknochens. Dm: 3,7 cm, D: 3 cm, G: 49,85 g. 8. An der Innenlinie der In situ-Perlenkette und der unteren Zahnreihe fand sich mit der Rückseite nach oben ein mit Öse versehener Solidus von Heraclius und Heraclius Constantinus (Abb. 6.51-52; Abb. 7.6), mit der gerippten silbernen Aufhängeöse in Richtung Schädel. ${ }^{25}$ „Konstantinopel, Offizin 5. Avers: dd NN hERAC[LIUS ET hERA CON]ST PP AV - zwei Frontalbüsten. Links der bärtige Kaiser, rechts sein bartloser Sohn. Beide tragen ein Diadem mit Kreuz und eine Chlamys, die von einer Fibel über der rechten Schulter zusammengehalten wird. Oben in der Mitte ein Kreuz. Revers: VICTORIA I AVGY E - Kreuz auf Stufen. In der Exergue CONO[B]. Mit einer silbernen, gerippten Hängeöse. Nase, Haarlocken und Bart bzw. ein Teil der Averslegende abgegriffen. Durchm. 20 mm. Gewicht mit der Hängeöse 4,55 g. MIB 11 (616-625), wobei die 8-förmige Fibel des Heraclius eine im MIB nicht vorhandene Variante dieser Emission darstellt." ${ }^{\text {“26 }}$

Trachtgegenstände. 9. Silberohrring mit großem Kugelanhänger in fragmentarischem Zustand (Abb. 5.3) an der linken Schädelseite bzw. der Stelle des linken Schlüsselbeins. Dem Kugelanhänger aus zwei Halbkugeln schloss sich der Ohrring durch ein aus zwei Hälften zusammengepasstes Glied aus vier Halbkugeln an. Kugelanhänger-Dm: $2 \mathrm{~cm}$. 10. Silberohrring mit großem Kugelanhänger in fragmentarischem Zustand (Abb. 5.4) an der Stelle der an der rechten Seite der Schädelknochen verschobenen Knochen sowie hinter dem Ende des rechten Oberarmknochens und neben dem dritten Wirbel. Dem Kugelanhänger aus zwei Halbkugeln schloss sich der Ohrring ebenfalls durch ein aus zwei Hälften zusammengepasstes Glied aus vier Halbkugeln an. Kugelanhänger-Dm: $2 \mathrm{~cm} .11-25$. In der Umgebung des durch Tiergang leicht gestörten, schlecht erhaltenen Schädels und des rechten Schlüsselbeins 15 quadratische, aus Bronze- und Goldblech zusammengepresste Beschläge mit mehrfach gebogenem Rand (Abb. 6.1-16; Abb. 7.5). Die Mehrheit der Beschläge, neun, lagen mit der Vorderseite nach oben, die Übrigen nach unten. Ihre Vorderseite zieren aneinandergefügte Kettenglieder. Die goldene Oberfläche der Beschläge ist unterschiedlich stark abgegriffen, die der am stärksten abgegriffenen ist silbrig glänzend. Ihrer Aufnä${ }^{24}$ LÖRINCZY 1992a, 90-100; LÖRINCZY 1995, 399-400;
LÖRINCZY-STRAUB 2004, 307-317; LÖRINCZY-STRAUB 2005, 137-139.
${ }^{25}$ Die Münze war nicht auf die Perlenhalskette gefädelt, wie Péter Somogyi erwähnt (SOMOGYI 1997a, 82).

${ }^{26}$ SomOGYI 1997a, 82-83. 


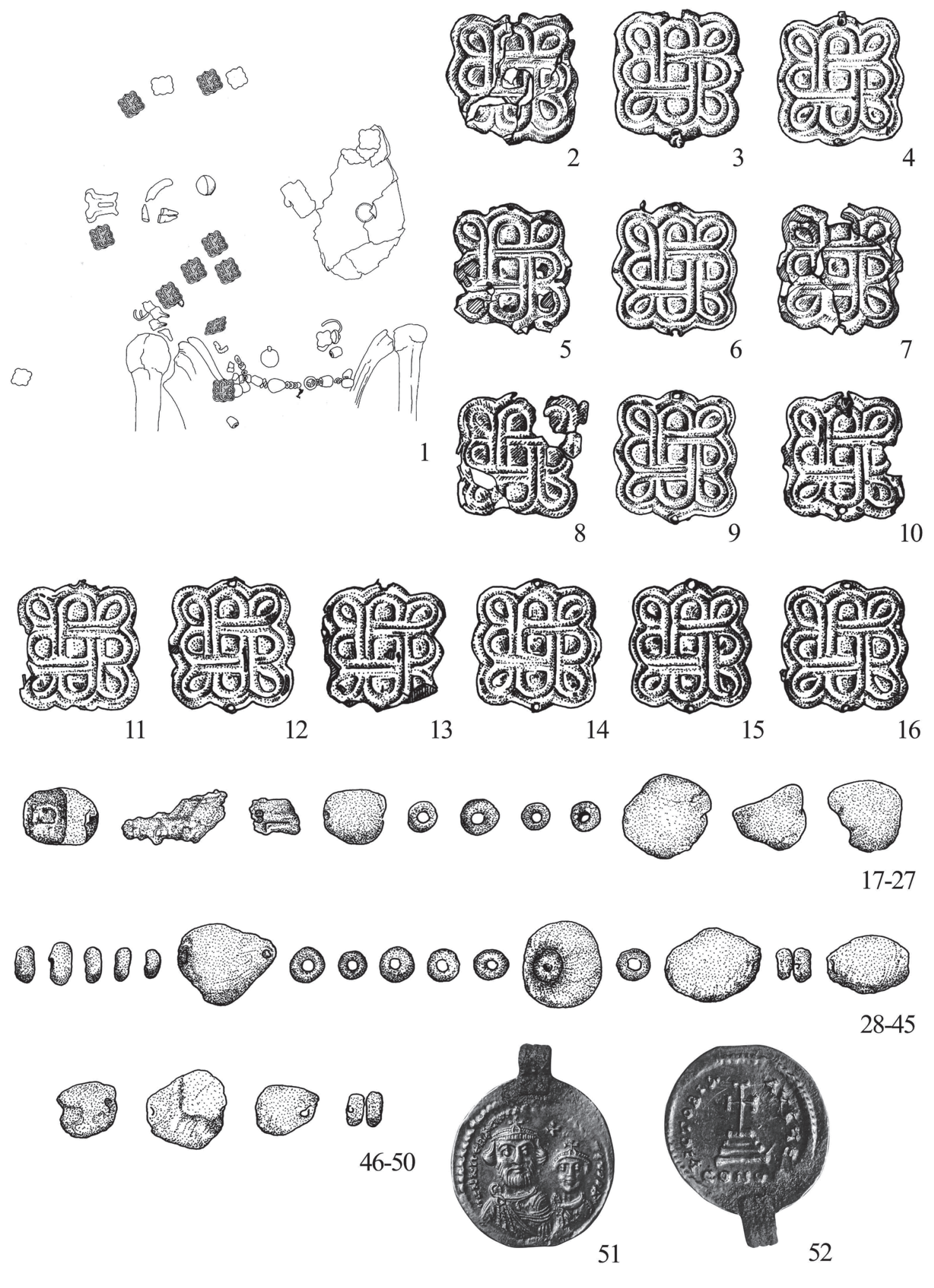

Abb. 6. Szegvár-Oromdülő Grab 761 
hung dienten Löcher auf ihrem Rand. Auf der Rückseite der an der linken Schädelseite mit der Rückseite nach oben gefundenen Beschläge (Abb. 6.12-13) saß je ein kleiner (fingernagelgroßer), mit Eisenoxyd konservierter Lederrest. Aufgrund der Pressspuren auf der Beschlagrückseite wurden sie sehr wahrscheinlich auf einem Pressmodel hergestellt. L: 2,4 cm, B: 2,2 cm, D: 0,25 cm. Halskettenperlen im Umriss des Kiefers, in situ. Die Glasperlen imitieren die Farben des Bernsteins. Ihre Beschreibung in der Reihenfolge der Auffädelung: 26. Deformierte säulenförmige Bernsteinperle mit ungleichen Seiten und dreieckigem Querschnitt (Abb. 6.17), mit konischer Bohrung. L: 0,6-1,0 $\mathrm{cm}, \mathrm{B}: 1,1 \mathrm{~cm}, \mathrm{D}:$ 0,7 cm, Bohrungs-Dm: 0,2-0,25 cm. ID.No. 1283. 27-28. Zwei Eisenfragmente (Abb. 6.18-19) in der Linie der Perlen, wahrscheinlich die Fragmente des Halskettenverschlusses. 29. Deformierte säulenförmige, abgewetzte, matte Bernsteinperle mit viereckigem Querschnitt (Abb. 6.20), mit schwach zylindrischer Bohrung. L: 1,15 cm, B: 1,05 cm, D: 0,58 cm, Bohrungs-Dm: 0,15-0,2 cm. ID.No. 1284. 30-33. Vier bräunlich ockergelbe, raue, deformiert gestaucht kugelförmige, opake Glaskugeln mit abgenutzter Glasur (Abb. 6.21-24) und zylindrischer Bohrung. L: 0,2-0,32 cm, Dm: 0,5-0,65 cm, Bohrungs-Dm: 0,2-0,22 cm. ID.No. 1285-1288. 34. Deformierte viereckig säulenförmige, abgenutzte, matte Bernsteinperle ( $A b b .6 .25)$ mit schwach zylindrischer Bohrung. L: 1,3 cm, B: 1,1 cm, D: 0,65 cm, Bohrungs-Dm: 0,2 cm. ID.No. 1290. 35. Deformierte ungleichmäßig dreieckige, lange säulenförmige Bernsteinperle $(A b b .6 .26)$ mit konischer Bohrung. L: 0,95-1,3 cm, B: 1,2 cm, D: 1,08 cm, Bohrungs-Dm: 0,25-0,3 cm. ID.No. 1291. 36-40. Fünf bräunlich ockergelbe, raue, deformierte, gestaucht kugelförmige, opake Glasperlen mit abgenutzter Glasur (Abb. 6.28-32) und zylindrischer Bohrung. L: 0,21-0,4 cm, Dm: 0,51-0,65 cm, Bohrungs-Dm: 0,2-0,25 cm. ID.No. 1292-1296. 41. Deformierte, rechteckig säulenförmige, abgenutzte, matte Bernsteinperle (Abb. 6.27) mit zylindrischer Bohrung. L: $1,75 \mathrm{~cm}, \mathrm{~B}: 1,4 \mathrm{~cm}, \mathrm{D}: 1,1 \mathrm{~cm}$, BohrungsDm: 0,2 cm. ID.No. 1297. 42-50. Neun bräunlich ockergelbe, raue, gestaucht kugelförmige, opake Glasperlen mit abgenutzter Glasur (Abb. 6.34-40, 43-44) und konischer Bohrung. L: 0,21-0,4 cm, Dm: 0, 58-1,61 cm, BohrungsDm: 0,2-0,58 cm. ID.No. 1298-1303, 1305, 4777-4778, 5828. 51. Deformierte, viereckige lange säulenförmige Bernsteinperle (Abb. 6.45) mit zylindrischer Bohrung. L: 1,55 cm, B: 1,45 cm, D: 0,7 cm, Bohrungs-Dm: 0,21 cm. ID.No. 1304. 52-53. Zwei bräunlich ockergelbe, raue, gestaucht kugelförmige, opake Glasperlen mit abgenutzter Glasur und zylindrischer Bohrung. L: 0,2-0,3 cm, Dm: 0,6 cm, Bohrungs-Dm: 0,25 und 0,21 cm. ID.No. 13071306. 54. Deformierte, viereckige lange säulenförmige Bernsteinperle (Abb. 6.45) mit schwach konischer Bohrung. L: 1,45 cm, B: 1,02 cm, D: 0,95 cm, Bohrungs-Dm: 0,15-0,2 cm. ID.No. 1308. 55-56. Zwei gleichschenklig dreieckige, deformierte, lange säulenförmige Bernsteinperlen (Abb. 6.46-47) mit zylindrischer Bohrung. L: 1,25 und $1 \mathrm{~cm}, \mathrm{~B}: 1,25$ und 0,9 cm, D: 0,8 cm, Bohrungs-Dm: 0,2 und 0,22 cm. ID.No. 1310-1309. 57. Ungleichseitig dreieckiges, langes säulenförmiges Bernsteinperlenfragment (Abb. 6.48) mit zylindrischer Bohrung. L: 0,751,05 cm, B: 0,9 cm, D: 0,6 cm, Bohrungs-Dm: 0,3 cm. ID.No. 1311. 58-59. Zwei gestaucht kugelförmige, bräunlich ockergelbe, raue, opake Glasperlen mit abgenutzter Glasur (Abb. 6.49-50) und zylindrischer Bohrung. L: 0,3 und 0,21 cm, Dm: 0,5 und 0,55 cm, Bohrungs-Dm:0,15 und 0,21 cm. ID.No. 1312-1313. 60. Rechteckige Eisenschnalle (Abb. 5.6) auf dem rechten Oberschenkelhals. Der Schnallendorn zeigte in Richtung der rechten Handknochen. L: $4,4 \mathrm{~cm}, \mathrm{~B}: 3,4 \mathrm{~cm}$.

Aufgrund der Stollengräber von Szegvár können die Merkmale dieses Grabtyps folgendermaßen zusammengefasst werden. Das Stollengrab ist eine vom allgemeinen Schachtgrab abweichende Grabform, die von ihrer Struktur her - dem Nischengrab ähnlich - eine zusammengesetzte Grabgrube ist. Sie bestand aus einem rechteckigen, von der Oberfläche aus eingetieften Schacht mit in Richtung Stollen leicht abschüssigem Boden und dem in Verlängerung der Längsachse in eine der kurzen Seiten eingeschnittenen, allgemein schräg nach unten eingetieften - selten waagerechten - Stollen. Seine vollständige Länge überstieg oft sogar $4 \mathrm{~m}$ und die am Ende des Stollens gemessene größte Tiefe konnte auch 3 m erreichen.

Der Fleck der von der Oberfläche eingetieften Schächte der Stollengräber von Szegvár zeichnete sich oft auch schon im dunklen Naturboden unter dem Humus gut ab, allgemein als sehr heller (gelber) Fleck, oft sogar auch noch im gewachsenen Boden heller als die Umgebung. Die Erklärung dafür ist, dass beim Graben des stark hinabführenden Stollens auch die tieferen, helleren Schichten des gewachsenen Bodens erreicht wurden und der aus der Tiefe des Stollens geförderte gewachsene Boden oben auf den Grabhügel gelangte. Es kam vor, dass nur ein Drittel des Schachtfleckes die helle Auffüllung zeigte. Auch das wies schon auf den Stollen hin, dann hatte man mit dem helleren Sand aus dem Stollen beim Zuschütten die vom Stollen entferntere Hälfte der Schachtgrube aufgefüllt.

Oft war festzustellen, dass sich in der Verlängerung der Längsachse des scharf konturierten Schachtfleckes - also über dem Stollen - ein ovaler oder runder Fleck mit verwischtem Umriss - wie bei den Nischengräbern - im 

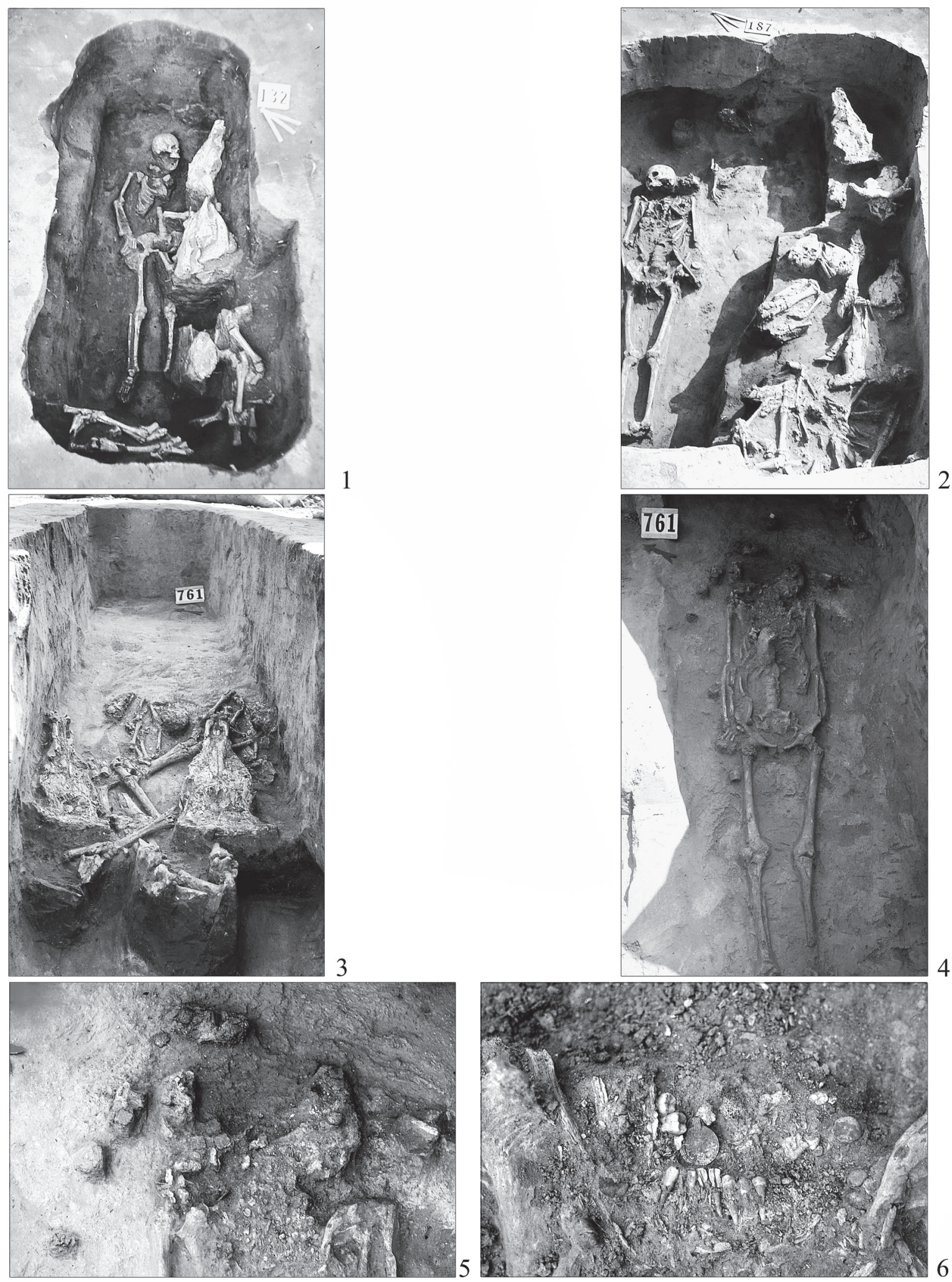

Abb. 7. Szegvár-Oromdülő. 1: Grab 132; 2: Grab 187; 3-6: Grab 761 
lich gehalten werden, dass sich die Arten der Gestaltung der frühawarenzeitlichen Stollengräber im Gebiet östlich der Theiß bei den Stollengräbern im Gräberfeld von Szegvár finden lassen. Deshalb besteht ein guter Grund, zum Beispiel das Reitergrab von Sânpetru German (Rumänien) ${ }^{34}$ und auch das von Szegvár-Sápoldal ${ }^{35}$ für Stollengräber zu halten. In diesen Fällen wurden die Stollen - abweichend vom allgemeinen Brauch - am Nordostende des Schachtes angelegt. ${ }^{36}$ In diese Stollen wurden aber die in den Sarg gelegten Toten mit dem Kopf nach vorn geschoben, so dass die der Himmelsrichtung entsprechende Lage der Toten mit der Orientierung der übrigen Bestattungen des Gräberfeldes übereinstimmte.

Die frühawarenzeitlichen Stollengrabbestattungen liegen im von Körös, Theiß und Aranka umgrenzten Gebiet, in überwiegener Mehrheit im Streifen entlang der Theiß und Maros. Das Weiterleben der Gemeinschaften, die in Stollengräbern bestatteten, hat sich bei der Auswertung der Bestattungssitten erwiesen. ${ }^{37}$ Die in der späten Periode auch in Stollengräbern bestattende Bevölkerung ließ sich auch in von der Theiß und Maros entfernteren bzw. solchen Gebieten nieder - z. B. am rechten Theißufer (Bácska-Szokolác, Szeged-Makkoserdő), nördlich der Körös (Rákóczifalva-Kastélydomb) -, wo bis dahin keine Gemeinschaften mit solcher Sitte lebten. In der späten Periode kann der Siedlungsschwerpunkt dieser Gemeinschaften in der Region südlich der Körös, im Raum SzarvasOrosháza, gelegen haben.

Zwar war das Stammgebiet der Praktizierung dieser Bestattungssitte in der Früh- und Spätawarenzeit gleicherweise das Gebiet östlich der Theiß, doch weisen zunehmend mehr Angaben darauf hin, dass mit dem vereinzelten Vorkommen der Grabform - und so vermutlich mit schwacher Migration der die Sitte übenden Gemeinschaften von östlich der Theiß nach der Frühawarenzeit - in den Innengebieten der Region zwischen Donau und Theiß bzw. auch im Uferstreifen rechts der Donau zu rechnen ist. ${ }^{38}$

\section{DIE RÄUMLICHE TRENNUNG DER TOTEN UND DER MIT IHNEN BESTATTETEN TIERBEIGABEN}

In fast allen Gräbern von Szegvár konnte die räumliche Trennung des Toten und der mit ihm bestatteten Tierbeigaben beobachtet werden, um ihn von den im Schacht - oder in dessen oberem Niveau - abgelegten Tierbeigaben abzusondern. Deren variable Formen sind bei den Schachtgräbern die Gräber mit Seitenrillen oder mit Seitenstufen bzw. die Nischen- und Stollengräber.

In den Nischen- und Stollengräbern von Szegvár findet sich oft am Ende des Schachtes zur Nische und zum Stollen hin, unmittelbar vor ihrem Eingang eine dunklere Füllung als die des Schachtes, oftmals schwarz mit braunen Pünktchen und fettig anzufühlen. Dies weist auf den Rest des Tierfells hin, mit dem der Eingang von Nische und Stollen geschlossen wurde. In diesem Fell wurden nie darin belassene Tierknochen gefunden. Bei mehreren Gräbern konnte auch festgestellt werden, dass irgendein steiferes Material, zum Beispiel Bretter, an den Eingang gestellt worden war, da die das Tierfell andeutende Auffüllung am Stolleneingang in vertikaler Ebene endete. Auch die manchmal quer laufende Rinne vor dem Stolleneingang deutet das einst vor dem Eingang stehende Brett an. ${ }^{39}$

Die oftmals gerade verlaufende Innenseite der den Nischeneingang schließenden schwarzen Auffüllung weist auf das Vorhandensein eines Sarges hin.

\section{ÜBER DIE PARTIELLEN TIERBESTATTUNGEN}

In den Gräbern des Gräberfeldes von Szegvár war die partielle Tierbestattung allgemein verbreitet. 375 Gräber enthielten den Überrest eines partiellen oder ganzen Tieres. Außer den acht vollständigen Pferden kamen von annähernd 400 Rindern, etwa 600 Schafen und Ziegen sowie mehr als 100 Pferden die abgezogenen Reste zum Vorschein.

\footnotetext{
${ }^{34}$ DÖRNER 1961.

${ }^{35}$ BÓNA 1979; BÓNA 1980.

${ }^{36}$ LÖRINCZY 1994, 325, Anm. 32, 328, Anm. 36.

${ }^{37}$ BENDE 2006, 90.

${ }^{38}$ LŐRINCZY-STRAUB 2006, 285.
}

${ }^{39}$ Beispielsweise Grab 81, Grab 100: LŐRINCZY-STRAUB 2005, 139; LŐRINCZY 1992a, 90, Abb. 8. Die Platte vor dem Stollen war nie aus Stein, wie das im Fall vom Szegvárer Grab 100 geschrieben wurde (VIDA 2003, 304, Abbildungsunterschrift von Fig. 37). 
Beim Abziehen der Tiere war die hier verwendete Technik die deformierte Variante, in der Weise, dass beim Abziehen außer dem Schädel die in der Haut belassenen Langknochen nicht bei den Gelenken ausgelöst, sondern am distalen Ende der Tibiae und Radien abgehackt wurden.

Die Reihe der frühawarenzeitlichen Gräberfelder/Gräber mit partiellen Tierbestattungen konnte nach der ersten Zusammenstellung ${ }^{40}$ sogar mehrmals ergänzt ${ }^{41}$ bzw. mit der Veröffentlichung neuer Gräber erweitert werden. ${ }^{42}$

Unter den frühawarenzeitlichen Fundorten im Gebiet östlich der Theiß haben wir bei 110 von ihnen sichere Angaben darüber, dass in den Gräbern partiell bestattete Tierreste lagen - ein Zeugnis dafür, dass die Tierbeigaben für die überwiegende Mehrheit der Gräberfelder typisch waren. Die partielle Tierbestattung war im hier behandelten Gebiet häufig, aber die Gräberfelder der Gemeinschaften, in denen sie fast allgemein genannt werden kann, liegen im Gebiet zwischen Körös, Tisza und Aranka. Diese Sitte kommt, wenn auch selten, nördlich der Körös vor, fehlt aber in den südlich der Aranka gefundenen Gräberfeldern fast völlig.

Eine große Zahl von Tierknochen aus alten Ausgrabungen kann heute nicht mehr untersucht werden. Unter den nur selten in Museumssammlungen gekommenen wenigen Tierknochenüberresten finden sich die zerschnittenen Fragmente von Radius und Tibia, die auf deformierte partielle Tierbestattungen hinweisen. ${ }^{43} \mathrm{Oft}$ gibt es nur in Aufzeichnungen solche Hinweise, aufgrund derer man an partielle Tierbestattung denken kann, wie zum Beispiel: „In der oberen Schicht des Grabes kamen ein Tierschädel und gespaltene Tierknochen zum Vorschein. “44 Oder einzelne Bemerkungen alter Grabbeschreibungen weisen auf eine Deformierung hin: z. B. gespaltene Tierknochen, im Zustand des Totenschmauses gefundene Tierknochen in der Füllerde, zerstückelte Pferdeknochen usw.

Im Gebiet zwischen Körös, Theiß und Maros hat sich in der zweiten Hälfte der Awarenzeit die Praxis des Abziehens bei der partiellen Tierbestattung geändert. Die Verstümmelung der Beinenden wird - nach gewissem zeitlichem Hiatus - von der Auslösungsform abgelöst, bei der die proximalen Enden der Vorder- und Hinterbeinmittelknochen sorgfältig an den Gelenken ausgelöst wurden und die Beinenden unbeschädigt in die Gräber kamen. ${ }^{45}$

\section{KERAMIKGEFÄSS IM GRAB}

In jedem vierten Grab des Gräberfeldes von Szegvár-Oromdủlỏ lagen Keramikgefäße, d. h. annähernd 120 Bestattungen enthielten Gefäßbeigaben. Handgeformte Gefäße mit Trichterrand, engem Hals und oft mit Tonglasur bedeckt erhielten Kinder und Alte, Frauen und Männer bei ihrer Bestattung gleichermaßen. Die überwiegende Mehrheit der Gefäße fand sich - wie auch die schon bisher bekannt gegebenen Bestattungen illustrieren (Grab 1, 100, 126, 130, 165, 692, 870 usw.) - neben dem Schädel (Abb. 4.1). In den Schacht- und Stollengräbern standen sie allgemein hinter dem Schädel bzw. an dessen rechter Seite, dagegen bei der überwiegenden Mehrheit der Nischengräber neben seiner linken Seite, vor dem Nischeneingang, immer außerhalb des Sarges.

Wie die partiellen Tierbestattungen, ist auch die Grablege der Keramikgefäße als Beigabe eine Eigentümlichkeit, die bei der Mehrheit der frühawarenzeitlichen Bestattungen im Gebiet östlich der Theiß vorkommt. ${ }^{46}$ Von den alten Freilegungen sind unter anderem Mokrin-Vodoplav (Serbien $)^{47}$ zu erwähnen, wo in jedem fünften Grab eine Gefäßbeigabe vorkam, immer am Schädel, ${ }^{48}$ sowie die Gräber des Gräberfeldes Tiszavasvári-Koldusdomb, ${ }^{49}$ wo bei der Hälfte der freigelegten Bestattungen ein Gefäß zum Vorschein kam, in den beobachteten Gräbern immer beim Schädel. ${ }^{50}$ Auch für die Mehrheit der neueren freigelegten Gräber ist die Keramikgefäßbeigabe typisch, gleichfalls am Schädel: z. B. Felnac/Fönlak-Magaspart (Rumänien); Gyula, Fo. 511; Hódmezővásárhely-Kishomok, Mérai porta; Nyíregyháza, Moszkva u. 9 (Milchbetrieb); Tiszavasvári-Kashalom-dűlő usw. ${ }^{51}$

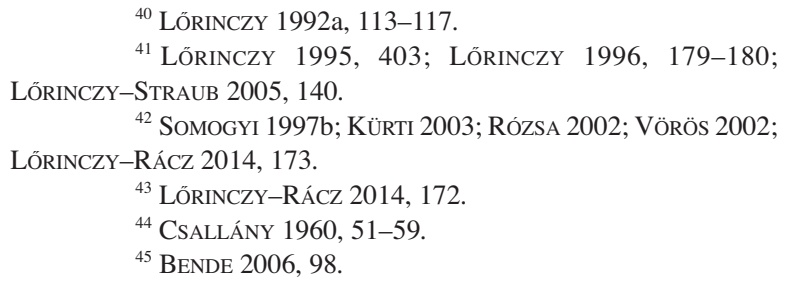

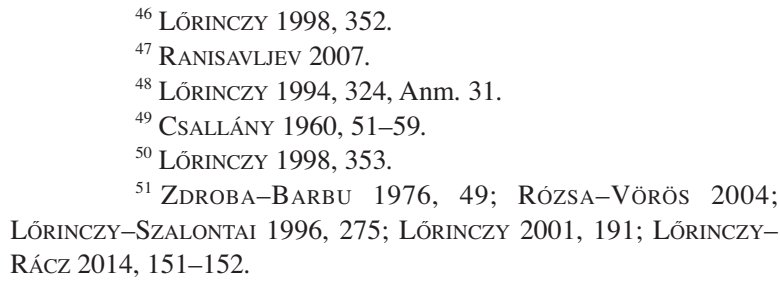


Im Arbeitsgebiet weiß man bisher von Keramikgefäßen an annähernd 100 frühawarenzeitlichen Fundorten. Die bekannt gewordenen ca. 250 Gefäße bedeuten, dass etwa in jedes fünfte Grab eines gelegt wurde. Das Abstellen des Gefäßes am Kopf war im Bestattungsritus der frühawarenzeitlichen Gemeinschaften im Gebiet östlich der Theiß ein sehr festes, traditionelles Element.

Im Gebiet zwischen Körös, Theiß und Maros betrug der Anteil der vorkommenden Keramikbeigaben in Gräbern aus der zweiten Hälfte der Awarenzeit ca. $8 \%$. Dabei übersteigt die Zahl der den Frauen beigegebenen Gefäße bedeutend die der bei den Männern und Kindern stehenden. Der Platz der Keramikbeigaben waren in mehr als der Hälfte der Fälle die Beine, vor allem der Bereich der Füße, und häufig, aber wesentlich seltener als bei den frühawarenzeitlichen Fällen, war das beim Kopf stehende Gefäß. Die Umgebung des Kopfes war der zweithäufigste Bereich, der aber doch einzelne Fundorte charakterisiert. All das bietet auch eine chronologische Erkenntnis: Das Abstellen der Gefäße am Schädel ist im Arbeitsgebiet in der zweiten Hälfte des 7. Jahrhunderts am typischsten und seine Häufigkeit nimmt gegen Ende der Epoche immer mehr ab. ${ }^{52}$

\section{DIE SPEISEBEIGABEN - LENDEN-, KREUZ- UND SCHWANZSTÜCKE VOM SCHAF}

Im Gräberfeld von Szegvár lagen in 87 Gräbern - $15 \%$ der Gesamtzahl - Kreuzbein, Schwanz- und Lendenwirbel vom Schaf gesondert oder zusammen als Überrest der Speisebeigabe. Bei der Bestattung legte man die Lenden-, Kreuz- und Schwanzstücke in allen Fällen neben den Schädel, meistens in den Sarg. Vom Gräberfeld in Szegvár-Oromdủlő wurden folgende Bestattungen mit Knochen auch der Lendenregion des Schafes vorgestellt: Grab 1, 81, 100, 109 und $130 .{ }^{53}$

In den frühawarenzeitlichen Bestattungen des Gebietes östlich der Theiß sind auf Speisebeigaben hinweisende Tierknochen selten, wo man sie aber findet, sind es überwiegend Schafkreuzbein (sacrum), Schwanz- (vert. caudalis) und Lendenwirbel (vert. lumbalis) gesondert oder zusammen, fast immer am Schädel. ${ }^{54}$

Schafkreuzbeine können aus alten Freilegungen bzw. unter unsicheren Umständen bekannt gewordenen Bestattungen nur schwer belegt werden, denn auf die in den Gräbern vorkommenden weniger gut erhaltenen, unauffälligen, aus einigen Wirbeln bestehenden Körperteile wurde man kaum aufmerksam. ${ }^{55}$ Seltene Fälle sind der von János Banner freigelegte Gräberfeldteil von Nagykamarás, wo er bei Grab 17 und auch 18 ein Schafkreuzbein notiert hatte, ${ }^{56}$ sowie das von Lajos Kiss freigelegte Grab 1 von Tiszabercel-Vékásdülő, in dem $20 \mathrm{~cm}$ links vom Schädel, außerhalb des Sarges ein Schafkreuzbein lag. ${ }^{57}$

Die obigen Gräber haben eher nur Signalwert. Wahrscheinlich spiegeln sie nicht die einstige Wirklichkeit, weil Schafskreuzbeine in den frühawarenzeitlichen Bestattungen im Gebiet östlich der Theiß weit häufiger als Speisebeigaben vorgekommen sein werden. ${ }^{58}$ Darauf weisen die Knochenreste der Speisebeigaben hin, die in den Bestattungen der neueren Freilegungen gefunden wurden. In Tiszavasvári-Kashalom-dülő Grab 34 wurden zum Beispiel sechs Schwanzwirbel eines Schafes linksseitig vom Schädel, in anatomischer Ordnung gefunden. ${ }^{59}$

In der zweiten Hälfte der Awarenzeit leben gewisse Elemente der frühawarenzeitlichen Bestattungssitten - im gegebenen Fall die Schafslendenregion als Speisebeigabe - eindeutig im älteren Horizont der Gräberfelder der späteren Periode des Gebietes zwischen Körös, Theiß und Maros weiter ${ }^{60}$ Dies belegt das Gräberfeld von SzékkutasKápolna-dülő, wo in 43 Gräbern, oder das Gräberfeld von Pitvaros, wo in 19 Gräbern Kreuzbein und Wirbel gefunden wurden, als Hinweis auf Lenden-, Kreuz- und/oder Schwanzstïcke vom Schaf. ${ }^{61}$

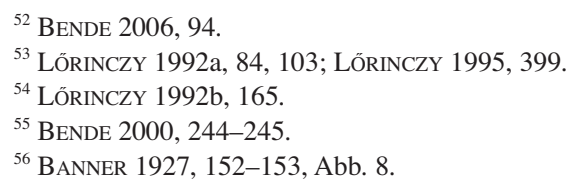

\footnotetext{
${ }^{57}$ CSALLÁny 1960, 34

${ }^{58}$ LÖRINCZY 1998, 344.

${ }^{59}$ LÖRINCZY-RÁCZ 2014, 151.

${ }^{60}$ BENDE 2000, 245.

${ }^{61}$ Bende 2003a, 322.
} 
ERDE AUF DEM GRAB ODER GRABHÜGEL?

Für eine anschauliche Charakterisierung der Ausmaße der Grabform und mittelbar der gesellschaftlichen Stellung der bestatteten Toten kann eine mit Maßangaben durchgeführte Rauminhaltsberechnung geeignet sein. ${ }^{62}$ Bei den Gräbern von Szegvár sind wir aber zu der Folgerung gelangt, dass es keinen Sinn hat, die Rauminhaltsangaben der verschiedenen Grabtypen mechanisch zu vergleichen. Denn zum Beispiel bei den Stollengräbern können die Größe des Schachtes außer dem Platzbedarf der darin unterzubringenden Tiere auch solche praktischen Gesichtspunkte bestimmt haben, wie der leichte Zugang des Stollens, während die Stollengröße auch von der Größe der unterzubringenden Sarges beeinflusst werden konnte. ${ }^{63}$

Die Gestaltung der für das Gräberfeld von Szegvár typischen zusammengesetzten Grabgruben hatte für das Gesamtbild von Gräbern und Gräberfeld eine praktische Konsequenz. Die bei der Bestattung im Sarg auf den Boden des Grabes, in die Nische oder den Stollen gelegten Toten schloss man im Fall des Schachtgrabes durch die quer darübergelegten Hölzer und bei den Nischen und Stollen durch das zusammengerollte Tierfell vor ihrem Eingang ab. Somit hat man den Stollen, die Nische und beim Schachtgrab die unterste Ebene bei der Bestattung nicht mit ausgehobener Erde aufgefüllt. Ähnlich war die Situation auch nach dem Ablegen der Tierüberreste. Auf dem obersten Niveau des Schachtes oder beim Nischen- und Stollengrab wegen des Platzanspruchs der im Schacht abgelegten Tierüberreste konnte ein großer Teil der aus dem Grab ausgehobenen Erde nicht wieder in die Grabgrube zurückgebracht werden.

Mit Berücksichtigung der durchschnittlichen Rauminhaltsangaben der verschiedenen Grabtypen blieben bei den Schachtgräbern wenigstens 1-1,5 $\mathrm{m}^{3}$, bei den Nischengräbern 2-2,5 $\mathrm{m}^{3}$ und bei den Stollengräbern 4,5-5 $\mathrm{m}^{3}$ Erde nach der Bestattung zurück. Aus dieser Erde schüttete man über den Toten keinen kleinen, sondern eher einen großen Grabhügel auf. Auf die einen weit größeren Bereich abdeckenden, großen Grabhügel deutet auch hin, dass im Gräberfeld von Szegvár die gruppenweise platzierten Gräber viel weiter als üblich voneinander entfernt sind. ${ }^{64}$

Diese Eigentümlichkeit ist nicht nur in Szegvár zu beobachten. Wie groß die Entfernung der Gräber voneinander ist, wird gut veranschaulicht, wenn man die Gräberfeldpläne von Székkutas-Kápolna-dủlö ${ }^{65}$ sowie von Kölked-Feketekapu $\mathrm{A}^{66}$ und Tiszafüred-Majoros ${ }^{67}$ vergleicht. Der sichtbare Unterschied kann aber auch mit Zahlen belegt werden. Auf dem als Muster gewählten, $25 \times 25 \mathrm{~m}$ großen Gebiet lagen in Szegvár 96, in Székkutas 105, dagegen in Kölked 225 und in Tiszafüred 240 Gräber. Diese Angaben zeigen eindeutig die unterschiedliche Dichte der Gräberfelder und erhöhen die Wahrscheinlichkeit, dass über den Gräbern in Szegvár größere und in Székkutas kleinere Grabhügel aufgeworfen wurden.

\section{KURZ ÜBER DIE BEZIEHUNG VON BESCHLÄGEN DES HAAR- ODER HAUBENSCHMUCKS MIT MÜNZEN, NISCHEN- UND STOLLENGRÄBERN}

In der Umgebung von Schädel und rechtem Schlüsselbein der im hier vorgestellten Grab 761 ruhenden juvenilen Frau fanden sich im von einem Tiergang gestörten Bereich 15 quadratische, aus Bronze- und Goldblech gemeinsam gepresste Beschläge mit mehrfach gebogenem Rand. Ihrer Aufnähung dienten Löcher an ihrem Rand, mit deren Hilfe sie - wie die in den Ecken von zwei Beschlägen erhaltenen Fragmente zeigen - auf Leder befestigt wurden. Falls die Beschläge nebeneinander aufgenäht wurden, konnten sie etwa $35 \mathrm{~cm}$ lang - demnach von Ohr zu $\mathrm{Ohr}$ - den Kopf der jungen Frau geschmückt haben. Falls die Beschläge weiter voneinander entfernt saßen, werden sie das den Kopf umgebende Band in ganzer Länge verziert haben.

Mit den awarenzeitlichen Kopfzierden der Frauen, darunter auch dem Diadem- oder Haarschmuck, hat sich mit dem Anspruch auf ihre Systematisierung Éva Garam beschäftigt. Sie hat die um den Schädel, auf der Stirn, der Schläfe bzw. unter dem Schädel gefundenen gepressten Beschläge den Kopfzierden zugeordnet. Ihrer Meinung

${ }^{62}$ DAIM 1987, 71-76; TOMKA 2003, 13.
${ }^{63}$ LÖRINCZY-STRAUB 2005, 139.
${ }^{64}$ Zugleich muss auch berücksichtigt werden, dass die aus-

${ }^{64}$ Zugleich muss auch berücksichtigt werden, dass die aus-
lockere Erdmasse nach der Bestattung einen größeren Platz gehobene, lockere Erdmasse nach der B
als die berechnete Menge beanspruchte.

\footnotetext{
${ }^{65}$ B. NAGY 2003, gefaltete Kartenbeilage.

${ }^{66}$ Kiss 1996, Abb. 7.

${ }^{67}$ GARAM 1995, gefaltete Kartenbeilage.
} 
nach kann die Funktion der Beschläge nicht eindeutig bestimmt werden, weil sie das Band zum Zusammenhalten der Haare ebenso zieren konnten wie das Schappel oder den Mützenrand. ${ }^{68}$

Éva Garam hat Recht damit, dass die Funktion der auf dem Schädel gefundenen Beschläge nicht eindeutig bestimmt werden kann. Sie können aber als wesentlicher Anhaltspunkt bei der Beurteilung der Frage des Geschlechts und des Alters der mit beschlagener Kopfzier Bestatteten gelten. Durch die Ergänzung des von Éva Garam zusammengestellten Fundort- und Gräberkatalogs des Haar- oder Haubenschmucks kommt man aufgrund der zur Verfügung stehenden Angaben zum Schluss, dass die entscheidende Mehrheit der mit Beschlägen auf dem Stirnband Bestatteten juvenil-adulte Frauen waren. ${ }^{69}$ Im Licht der neueren Angaben hat sich dies einerseits bestätigt, andererseits kann diese Feststellung insofern präzisiert werden, dass aufgrund der vorhandenen anthropologischen Angaben die große Mehrheit der mit beschlagenem Stirnband bestatteten frühawarenzeitlichen Frauen im Inf. II- und Ad. IAlter verstorben war. Die im Inf. II-Alter bestatteten Mädchen hatten mit Sicherheit nicht und die im Alter von 15-22 Jahren verstorbenen jungen Frauen gemäß der anthropologischen Untersuchung wahrscheinlich nicht geboren. Aus diesem Grund waren die mit Beschlägen verzierten Jungfernkränze wahrscheinlich der Kopfschmuck der jungen, heiratsfähigen Mädchen gewesen.

Von dem weit verzweigten Fragenkreis der awarenzeitlichen Jungfernkranzbeschläge im Karpatenbecken wird hier nur auf einige Details hingewiesen. Im Gräberfeld von Szegvár-Oromdülő wurden drei Typen von Beschlägen mit unterschiedlichem Muster zur Verzierung der Stirn aus Gräbern von 12-22-jährig verstorbenen Mädchen und jungen Frauen schon kurz erwähnt. ${ }^{70}$ Für die Beschläge von Grab 761 gibt es im Gräberfeld keine Parallele; aus dem Arbeitsgebiet können 16 Beschläge aus dem noch unpublizieren Gräberfeld Deszk G ${ }^{71}$ Grab 58 sowie 12 Beschläge aus Kiszombor $\mathrm{M}^{72} \mathrm{Grab} 26$ erwähnt werden. Zu diesen Beschlägen sind den Beschlägen ähnelnde Pressmodel des Goldschmiedegrabes von Adony ${ }^{73}$ bekannt.

Unter den Jungfernkränzen von östlich der Theiß finden sich alle drei von Éva Garam bestimmte Typen - mit Dreiergliederung (haselnussförmig), quadratisch und mit gebogenen Seiten ${ }^{74}-$, aber in größter Zahl gibt es die dreigliedrigen, rosettengemusterten Beschläge, neben denen noch der einzige ähnlich geformte Pressmodel von Kunszentmárton zu erwähnen ist. ${ }^{75}$

Ganz einzigartig ist die Situation, dass im Gebiet östlich der Theiß neun Gräberfeldteile bekannt sind, in denen von 15, auch Jungfernkranzbeschläge enthaltenden Gräbern in vier Bestattungen - Békéscsaba-Repülőtér ${ }^{76}$ Hódmezővásárhely-Kopáncs Grab 233, ${ }^{77}$ Kiszombor-Tanyahalom-dűlő Grab $16^{78}$ und Szegvár-Oromdủlő Grab 761 - Solidi ${ }^{79}$ von Heraclius und Heraclius Constantinus, geprägt zwischen 616 und 625 in Konstantinopel, aber in verschiedenen Offizinen bzw. auf unterschiedlichen Prägestöcken, gefunden wurden. Außer den Perlen gibt es vielleicht keinen weiteren Fundtyp, der in so großer Zahl in Gesellschaft von Münzen ans Licht gekommen ist. Aufgrund der vier Gräber mit Münze kann angenommen werden, dass die Sitte der Jungfernkränze mit Beschlägen in der Südhälfte des Gebietes östlich der Theiß wahrscheinlich auf die Wende des ersten und zweiten Viertels des 7. Jahrhunderts fällt und sie spätestens im zweiten Viertel des Jahrhunderts in die Erde gekommen sein werden. ${ }^{80}$

Die große Mehrheit der Bestattungen auch mit Münzen und Jungfernkranzbeschlägen waren Stollengräber. Das ist ein Hinweis darauf, dass die Münzen von 616-625 nicht nur die Zeit der Bestattung der beschlagenen Jungfernkränze, sondern auch die der Stollengrabsitte angeben. Auf ihren chronologischen Zusammenhang weist des Weiteren hin, dass sich von den Bestattungen mit Jungfernkranzbeschlägen im Gebiet östlich der Theiß sieben als Stollengräber erwiesen.

Im Gebiet östlich der Theiß kamen bisher an annähernd 40 Fundorten etwa 44 byzantinische Solidi zum Vorschein, von denen die meisten, die im 19.-20. Jahrhundert in Museums- oder numismatische Sammlungen kamen, zwar mit ihrem Fundort bekannt, aber Streufunde waren. ${ }^{81}$ Unter den Gräbern mit byzantinischen Goldmün-

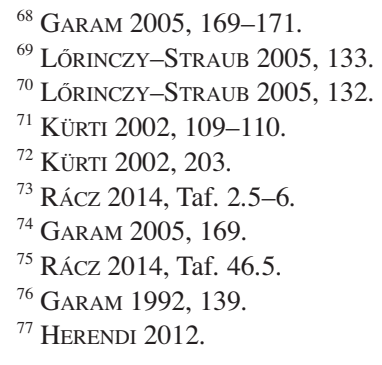

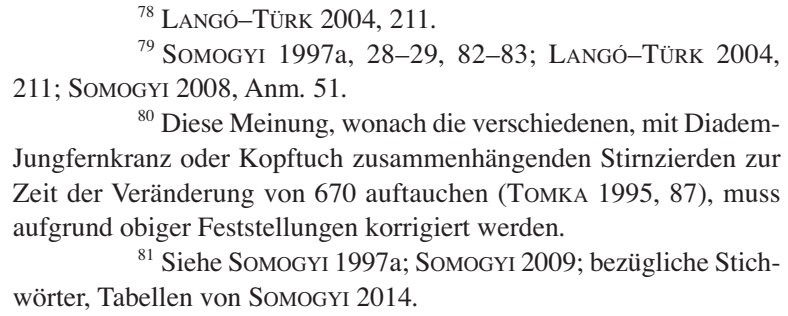
211; SomogYi 2008, Anm. 51.

${ }^{80}$ Diese Meinung, wonach die verschiedenen, mit DiademJungfernkranz oder Kopftuch zusammenhängenden Stirnzierden zur Zeit der Veränderung von 670 auftauchen (TomKA 1995, 87), muss aufgrund obiger Feststellungen korrigiert werden.

${ }^{81}$ Siehe Somogyi 1997a; Somogy 2009; bezügliche Stichwörter, Tabellen von SOMOGYI 2014. 
zen haben wir nur von 16 Bestattungen Informationen bezüglich der Grabform, deren Mehrheit schon bei Ausgrabungen gefunden wurde. Mehr als die Hälfte der bekannten Bestattungen, d. h. neun, waren Stollengräber, außerdem waren vier Schachtgräber, eines wahrscheinlich ebenfalls und nur zwei waren Nischengräber.

Die Münze in sechs von den neun Stollengräbern war ein Solidus von Heraclius und Heraclius Constantinus aus der Emissionsperiode 616-625, außerdem wurden ein Mauricius Tiberius- und zwei Phokas-Solidi gefunden. Grab 3 von Szegvár-Sápoldal schließt mit der Silberimitation einer Constans II.-Münze ${ }^{82}$ die Reihe der Stollengräber mit Münze im Gebiet östlich der Theiß ab. Diese Verteilung der Münzen belegt die kontinuierliche Sitte der Stollengräber in der Frühawarenzeit nicht eindeutig. Das Fundmaterial der Stollengräber mit vor 616 emittierten Münzen legt eher nahe, dass die Bestattung in Stollengräbern im zweiten Viertel des 7. Jahrhunderts unter den Bestattungssitten der Gemeinschaften im Gebiet östlich der Theiß aufkam. Sollte diese Beobachtung zutreffen, dann ist der „,eng“ datierbare Wert der Mauricius Tiberius- und Phokas-Solidi in diesem Fall sicherlich in Frage zu stellen. ${ }^{83}$

Eine ähnliche Tendenz wurde bei der Verwendung der Münzen mittels Durchlochung oder Henkelung als Schmuck beobachtet. Deren „Mode“ kann im zweiten Viertel des 7. Jahrhunderts bei der östlich der Theiß ansässigen Bevölkerung typisch gewesen sein, deshalb ist auch die strenge Datierung durch vor 616 emittierte und als Schmuck getragene Solidi fraglich. ${ }^{84}$

Wenn auch nur mittelbar, so weist zudem der Anteil der Fundorte und Gräber mit Nischen und der mit Münzen datierbaren Nischengräber darauf hin, dass die Stollengräber - im Gegensatz zu den Nischengräbern - erst im zweiten Viertel des 7. Jahrhunderts als Bestattungssitte erscheinen. Außer den an 16 Fundorten im Gebiet östlich der Theiß gefundenen 24 Nischengräbern sind in Szegvár-Oromdűlő annähernd 90, dagegen in Makó-Mikócsa-halom annähernd 150 Nischengräber bekannt. ${ }^{85}$ Von diesen Gräbern lag nur in einem, im Nischengrab 208 von Makó-Mikócsa-halom, eine byzantinische Münze: ein Solidus mit Öse von Mauricius Tiberius, emittiert 583/584-602. ${ }^{86}$ Der Vergleich der Nischen- und Stollengräber mit Münze zeigt, dass im Arbeitsgebiet bis zum ersten Viertel des 7. Jahrhunderts außer den Schachtgräbern in Nischengräbern bestattet wurde. Dann wurde die Verwendung dieses Grabtyps immer seltener und die neu aufgekommene Grabform, das Stollengrab - neben den Schachtgräbern - häufig. ${ }^{87}$

Wegen der kleinen Fallzahl kann der Beleg für diese Ansicht von der typochronologischen Untersuchung des Fundmaterials aus diesem Gebiet, von der Auffindung neuerer Gräber mit genügendem Datierungswert und der Analyse bisheriger Radiokarbonuntersuchungen erwartet werden.

\section{ÜBER DIE MÖGLICHKEITEN DER RADIOKARBONUNTERSUCHUNG}

In den vergangenen Jahrzehnten wurden an einem Muster des Knochenmaterials aus 15 Gräbern des Gräberfeldes von Szegvár konventionelle Radiokarbonmessungen in der Prähistorischen Abteilung des Naturhistorischen Museums Wien, im Umweltanalysenlabor des Atomkern-Forschungsinstitutes der Ungarischen Akademie der Wissenschaften Debrecen sowie die AMS-Datierung im Poznan Radiocarbon Laboratory vorgenommen.

Die Auswahl der Muster hatte den Zweck, die Datierung auf typochronologischer Basis mit den kalibrierten Angaben der bei der Radiokarbonuntersuchung erhaltenen Werte zu vergleichen. Unter den in die Untersuchung einbezogenen Gräbern waren auch drei Bestattungen, die Solidi von Heraclius und Heraclius Constantinus enthielten, die in den Jahren 616-625 geprägt worden waren.

Während mit der typochronologischen Untersuchung der Funde von Gräbern mit Münzbeigaben und mit Hilfe der byzantinischen Münzen der Gräber auf die mögliche Periode der Herstellung und Grablege der Gegen-

${ }^{82}$ Somogyi 1997a, 85-86.

${ }^{83}$ Péter Somogyi hat die mittelbare Datierung der Bestattungssitte in Stollengräbern aufgrund der in ihnen gefundenen Münzen schon vor zwanzig Jahren auf das erste Drittel des 7. Jahrhunderts gelegt. Ebendort behandelt er auch die Probleme der frühen ,,scharfen“ Datierung der Münze von Szegvár-Sápoldal ausführlich (SoMOGYI 1997a, 154-165).

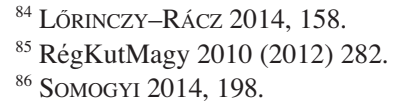

${ }^{87}$ Das andere Nischengrab ist Hajdúdorog-Városkert út Grab 1 (GARAM 1992, 142-143; LŐRINCZY 1996, Anm. 17; LŐRINCZYSTRAUB 2012). Die NNW-SSO-Orientierung, die in der SO-Seite des Grabes ausgehöhlte Nische und das im Schacht begrabene ganze Pferd sind in den frühawarenzeitlichen Bestattungssitten im Gebiet östlich der Theiß fremd. Diese Elemente des Bestattungsritus weisen jedes für sich und auch gemeinsam auf die fremde Abstammung der hier bestattenden Gemeinschaft hin. Deshalb muss dieses Nischengrab mit Münze anders beurteilt werden als die vorher genannten Nischen- und Stollengräber. 
stände geschlossen werden kann, lässt sich mit der Methode der Radiokarbondatierung der Todeszeitpunkt eingrenzen. Keine der Methoden ist unproblematisch, aber mit der Vergleichung der drei voneinander unabhängigen Datierungen kann die Richtigkeit eines Ergebnisses verifiziert oder ausgeschlossen werden ${ }^{88}$

Ein hervorragendes Beispiel für dieses Herangehen ist die Auswertung der vor nicht langer Zeit vorgenommenen archäologischen Analyse von Tiszavasvári-Kashalom-dülő Grab 34 bzw. Hajdúnánás-Fürjhalom Grab 12 und $19^{89}$ sowie der Angaben der Radiokarbonmessungen am Muster des Knochenmaterials der Gräber. ${ }^{90}$

\section{DIE BELEGUNGSZEIT DES GRÄBERFELDES VON SZEGVÁR-OROMDÚLŐ}

Den Beginn der Gräberfeldbelegung geben unter anderem die Fundensembles aus Grab 1 und 165 an. Dazu gehört der kleine, mit winzigen Granulaten verzierte goldene Ohrring mit Pyramidenanhänger, der Ohrring aus schlechtem Silber mit deformiertem Kugelanhänger, der Ohrring aus vier kleinen Silbergranulaten, die vier unterschiedlichen Busenagraffen, die oberflächenvergoldeten Busenscheiben, die drei verschiedenen, aus Silber gepressten Beschläge vom sog. Typ Martinovka der Fußbekleidung und die zu ihnen gehörige gepresste Bronzeschnalle. ${ }^{91}$ Der bisher einzigartige, steigbügelförmige Beingegenstand ${ }^{92}$ aus dem Grab hat zwar keinen Datierungswert, ist aber das Symbol der Periode, als die Mitglieder dieser Gemeinschaft wahrscheinlich schon die neue Errungenschaft des Reitens kannten, aber den Eisensteigbügel im Alltag noch nicht verwendeten.

Zur ersten Generation mochte die mature Frau mit leicht deformiertem Schädel in Grab 165 gehört haben, deren Gürtel eine silberne sog. Maskenriemenzunge mit schwach gebogenem Ende, Seitenleiste und durchbrochenem Muster zierte und eine kleine, annähernd quadratische Eisenschnalle schloss. Außerdem lag in dem Grab auch eine aus Bronzeblech gepresste kleine Schnalle mit Schildbeschlag. ${ }^{93}$

Die beiden Schachtgrabbestattungen haben mehrere gemeinsame Bezüge. Am Südwestende beider Gräber wurde je ein partieller Rest eines Kleinwiderkäuers gefunden. Daneben, vor den Fußknochen - nicht an der allgemein üblichen Stelle, neben den Armknochen - lagen die Spinnwirtel. Ihre derartige Lage im Grab ist auch im Gräberfeld von Szegvár eine Seltenheit und wahrscheinlich mit der frühen Datierung der Bestattungen zu verbinden.

Ihre Zugehörigkeit zur ersten Generation legen die in beiden Gräbern gefundenen Beigaben germanischen Charakters nahe. In Grab 1 ist dies das Metallzubehör des Kopfgeschirrs vom partiell bestatteten Pferd: Eisentrense mit gegossenen Bronzeringen und bronzener stilisierter Pferdekopf-Riemenklemme, gegossene Kugelkopf-Bronzeniete, kreuzförmige, geometrisch verzierte, gegossene Bronzeriemenverteiler mit vergoldeter Oberfläche, entenschnabelförmige gegossene Bronzeriemenzunge und aus Bronze gegossene sog. Schilddornschnalle. ${ }^{94} \mathrm{Zu}$ diesem Fundkreis gehört auch der vor den Beinknochen der 16-18-jährigen, aufgrund der morphologischen Merkmale als mongolid bestimmbaren Frau liegende, zusammen mit dem Spinnwirtel und der partiellen Schafbestattung gefundene, kleine zweireihige Beinkamm.

Das sandgemagerte scheibengedrehte Gefäß aus Grab 165 ist aufgrund seiner Ausführung und bikonischen Form ein Erzeugnis des gepidischen Gefäßhandwerks des 6. Jahrhunderts, ein fremdes Stück unter den frühawarenzeitlichen Grabkeramiken. ${ }^{95}$

Diese beiden Gräber gehören zu den allerersten des Gräberfeldes, deren Datierung in die Jahre nach 568, spätestens aber in die 570er Jahre das gemeinsame Vorkommen des oben aufgeführten Fundmaterials und der Bestattungssitten sowie die Lage beider Gräber (auf dem Hügelrücken) belegen.

Momentan kann der Belegungsbeginn des Szegvárer Gräberfeldes nur mit den Fundmaterialensembles aus Frauenbestattungen charakterisiert werden. Im bisher freigelegten Gräberfeldteil lassen sich den Frauengräbern der ersten Generation keine in diese Periode zu legenden Männerbestattungen zuordnen. Das bedeutet natürlich nicht, dass im letzten Drittel des 6. Jahrhunderts im Gräberfeld neben den Frauen nicht auch Kinder und Männer bestattet worden wären. Unserer heutigen Kenntnis nach kann die archäologische Hinterlassenschaft der in dieser Periode im Szegvárer Gräberfeld bestatteten Männer nicht mit Sicherheit in diese Periode datiert werden. Wenn auch nicht

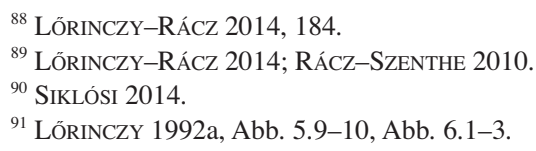

${ }^{89}$ LŐRINCZY-RÁCZ 2014; RÁCZ-SZENTHE 2010.

${ }^{90}$ SIKLÓSI 2014

${ }^{91}$ LÖRINCZY 1992a, Abb. 5.9-10, Abb. 6.1-3.

\footnotetext{
${ }^{92}$ LÖRINCZY 1992a, Abb. 3.7.

${ }^{93}$ LŐRINCZY 1998, Abb. 15.8-9, 11.

${ }^{94}$ LŐRINCZY 1992a, Abb. 3.1-6.

${ }^{95}$ LŐRINCZY 1998, Abb. 15.7, Abb. 16.4.
} 
hier, so lassen sich doch im Gebiet östlich der Theiß die Gräber einiger, noch im letzten Drittel des 6. Jahrhunderts bestatteter Männer nennen.

In Szentes-Lapistó lag an der linken Seite eines Männerskeletts im SO-NW orientierten, einsamen Nischengrab eines Hügels ein zweischneidiges Schwert. Im Schacht lag - linksseitig des Mannes - eine partielle Pferdebestattung mit dem Pferdeschädel neben den Beinknochen des Mannes, 20-25 cm höher als diese. Neben dem Pferdeschädel wurden unter anderem je eine Neben- und Hauptriemenzunge mit Maske aus durchbrochen verziertem Blech, zwei gegossene, symmetrisch schildförmige Silberbeschläge, ein rechteckiges Kupferklemmband, eine gegossene Bronzeriemenschlaufe und das $11 \times 13 \mathrm{~cm}$ große Stück eines Kettenpanzers gefunden. ${ }^{96}$

In Szentes-Derekegyházoldal fanden sich in der oberen Schicht eines NO-SW orientierten, einsamen Grabes partielle Tierbestattungen: Schädel und Beinknochen zweier Pferde, je eines Kalbes und Schafes. An der rechten Seite des adulten Mannes mit schwach mongolidem Einschlag ${ }^{97}$ lagen die beinernen Versteifungsplatten eines asymmetischen Reflexbogens. Die beiden Enden des Bogens bedeckten je drei und den Griff vier Platten. Zwischen den Bogengriffplatten und der Außenseite der rechten Handknochen lagen vier Eisenpfeilspitzen. Neben der Außenseite des rechten Beckens fand sich ein beinerner Knotenlöser. Zwischen den Beckenschaufeln und unteren Rippen befanden sich in der Linie des Bauches, quer zur Linie der Wirbelsäule, in gleicher Entfernung voneinander drei aus Bronzeblech geschnittene, zweiplattige Nebenriemenzungen mit gebogenen Seiten und leicht zugespitzem Ende. Von der Hauptriemenzunge blieb nur die Seitenleiste übrig. Außerdem lagen unter dem Kälberschädel fünf Wetzsteine und vier Stück aus Horn geschnitztes Werkzeug. Die Beigaben der Pferdebestattung: Scharniereisentrense mit Ringenden unter dem Pferdekiefer, außen neben dem linken Unterschenkel ein Steigbügelpaar mit Schlaufenösen und hinter der einen Steigbügelöse ein beinerner Zylinder zum Einklemmen des Steigbügelriemens. Eine Grabbeigabe war noch ein im frühawarenzeitlichen Fundmaterial im Gebiet östlich der Theiß als einzigartig geltender eiserner Schildbuckel neben dem Brustbein. ${ }^{98}$

In Hódmezővásárhely-Szárazér-dűlő wurde links neben dem in einem SO-NW orientierten Grab liegenden Mann in identischer Orientierung eine partielle Pferdebestattung gefunden. Den Brustkorbteil des Skeletts hatten Erdarbeiten vernichtet. Die Beigaben des Mannes: 1-2. Auf dem Rand der rechten Beckenschaufel ein punktkreisverzierter beinerner Taschenverschluss, darunter ein Feuerstein. 3. Auf dem Kreuzbein eine ovale Bronzeschnalle gepidischen Typs mit Eisendorn. 4. Auf dem Mittelfinger der linken Hand war der Abdruck eines dünnen Bronzefingerrings zu erkennen. Die Beigaben der partiellen Pferdebestattung: 5. Zweiring-Eisentrense in fragmentarischem Zustand. 6. Eisenring. 7. Zwischen den Pferdebeinknochen eine rechteckige Eisenschnalle. 8. Ebendort eine beinerne Riemenschlaufe. ${ }^{99}$

Szentes-Borbásföld. Bei der Fundrettungsfreilegung in dem Gebiet kam neben 20 Gräbern aus dem 10. Jahrhundert auch eine frühawarenzeitliche Bestattung zum Vorschein. In Grab 4 mit NNO-SSW-Orientierung war der Teil eines juvenilen Skeletts vom Becken nach oben vom Sandabbau vernichtet worden. Beigaben: 1. Fragmentarischer Eisengegenstand außen am rechten Fuß. 2. Eisenmesser außen am rechten Fuß, parallel mit ihm. 3. Waagerecht und senkrecht liegende Pferdebeinknochen $30 \mathrm{~cm}$ vom linken Unterschenkel. 4. In der obersten Schicht der Pferdeknochen lagen Schafknochen. Aller Wahrscheinlichkeit nach am gestörten Pferdeschädel kam ein durchbrochen verzierter Schalenguss-Silberbeschlag zum Vorschein. ${ }^{100}$

Über die im Karpatenbecken gefundenen Gürtel-, Schuhwerk- und Pferdegeschirrtypen mit Masken sind die ungarischen Archäologen allgemein der Ansicht, dass sie zu den frühesten Zeugnissen der Frühawarenzeit gehören. ${ }^{101}$ Selten kommen in einer Bestattung mehrere Exemplare vor, nicht einmal die Gürtelbeschläge in vollständigen Garnituren. ${ }^{102}$ Diese Beschläge treten in der ersten Phase der frühawarischen Periode auf. ${ }^{103}$ Das Fundmaterial variabler Ausführung hat Péter Somogyi vor allem gemäß der Goldschmiedepraxis (Technologie) und in zweiter Linie der Form geordnet. ${ }^{104}$ Csilla Balogh hat die von Péter Somogyi geschaffene typologische Einteilung der Maskenbeschlagtypen des Karpatenbeckens mit Einbeziehung der neuen Funde erweitert und überprüft. Dabei betrachtete sie bei der Gruppierung der Maskenbeschläge die Verzierung als erstrangigen Gesichtspunkt, als sekundären

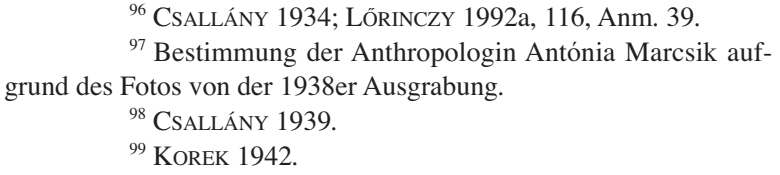

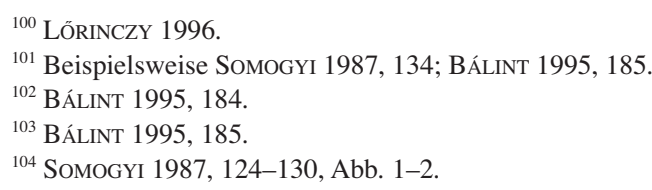

Acta Archaeologica Academiae Scientiarum Hungaricae 68, 2017 
die Form und bestimmte aufgrund dieser die Beschlagtypen. ${ }^{105}$ Wir haben bei den untersuchten Bestattungen die Betonung auf die Zusammensetzung der Grabensembles gelegt.

Aufgrund der archäologischen Funde aus der osteuropäischen Steppe stieß die Auswahl und sichere Bestimmung des Fundhorizontes der ersten Generation bisher auf Schwierigkeiten. Die hier vorgestellten Gräber wurden in den Jahrzehnten nach der awarischen Landnahme im Karpatenbecken, im letzten Drittel des 6. Jahrhunderts, angelegt. Darauf weist einerseits die Zusammensetzung der Funde aus den Gräbern hin. Ein Teil von ihnen hat osteuropäische, Steppenbezüge, ein anderer Teil hat Trachtelemente von byzantinischem Geschmack oder Herstellung, des Weiteren enthalten sie Beigaben lokaler, gepidischer Herkunft. An die Beschläge mit Steppenbezügen und den Schmuck byzantinischer Art konnten sie im zweiten Drittel des 6. Jahrhunderts noch in der osteuropäischen Steppe gelangt sein und sie von dort mitgebracht haben. Die Gegenstände gepidischen Typs ${ }^{106}$ beschafften sie sich im Karpatenbecken. So lässt sich in diesen Grabensembles das Aufeinandertreffen der gegenständlichen Hinterlassenschaft der aus der Steppe Gekommenen und der hier vorgefundenen Bewohnerschaft dokumentieren. Diese Fundensembles ,gemischter Zusammensetzung“ signalisieren den Fundhorizont der ersten Generation der aus der Steppe nach 568 ins Karpatenbecken umgezogenen Bevölkerung, in der sich solche befanden, die möglicherweise noch östlich der Karpaten geboren worden waren.

Die in diesen Horizont gehörenden Karpatenbeckenexemplare der Maskenbeschläge mit Steppenanalogien sind, obwohl sie einander ähneln, individuell geschaffen worden. Eben deshalb unterscheiden sie sich voneinander und bilden nie Garnituren. Dieser Fundhorizont bezeichnet die Periode, in der noch keine Gürtel- und Pferdegeschirrzierden hergestellt wurden - oder diese Bevölkerung noch keinen Zugang zu solchen hatte -, deshalb finden sich keine kompletten beschlagenen Gürtel- und Pferdegeschirrgarnituren. So zusammengesetzte Grabensembles sind nur sehr wenige bekannt. Es gibt keine Parallelen ihrer Zusammensetzung, weder im 500er Gräberfeld von Szegvár noch unter den Gräbern östlich der Theiß. Bei der Mehrheit dieser Grabensembles, im Gräberfeld es auch partielle Pferdebestattung gibt, fehlen die Eisensteigbügel.

Neben den Tracht- und Gebrauchsgegenständen unterschiedlicher Herkunft sind die in diesen Gräbern erkennbaren Bestattungssitten einheitlich. Dazu gehören die NO-SW-Orientierung (sehr selten NO-SW-Orientierung), die Einzelbestattung, die Schacht- oder Nischengrabform - aber nie Stollengrab -, die partielle Pferde- bzw. Tierbestattung, der partielle Rest von Kleinwiderkäuern am Fußende der Frauengräber sowie daneben liegende Spinnwirtel. In manchen dieser Grabensembles wurden einzelne Zubehörteile der Tracht (z. B. Riemenzungen) oder Gebrauchsgegenstände (z. B. Spinnwirtel, Beinkamm) nicht an der Stelle gefunden, an der man sie getragen hat.

Einzelne Gegenstände der Funde, die jenen Fundhorizont bedeuten, der Tracht und Grabbeigaben der ersten Generation charakterisiert, kommen auch in späteren Bestattungen vor, diese Grabensembles werden aber durch die jüngeren Funde in ihnen auf später als diese Periode datiert. Dafür werden hier zwei Beispiele genannt.

Für die durchbrochen verzierten, aus Silber gegossenen Nebenriemenzungen mit parallelen Seiten aus dem Fundensemble von Tolnanémedi ${ }^{107}$ findet sich eine hervorragende Parallele im Grabensemble von Szentes-Lapistó, aus Silberblech ausgeschnitten. Aber das mangelhafte Fundensemble von Tolnanémedi ${ }^{108}$ datieren die zusammengegossene Silberschnalle mit Schildbeschlag und Eisendorn sowie die rechteckigen, fransengemusterten Kupferblech-Pferdegeschirrbeschläge ${ }^{109}$ auf mindestens zwei Generationen spätere Zeit als das Grab von Szentes-Lapistó. ${ }^{110}$

Ähnlich verhält es sich mit dem Grabensemble von Manđelos (Serbien). ${ }^{111}$ Die gepresste Variante des dortigen, aus Silber gegossenen Fischschwanzbeschlages findet sich unter den Beschlägen der Fußbekleidung im schon genannten Grab 1 von Szegvár-Oromdülő. Bei der Auswertung des Manđelos-Grabes muss einerseits berücksichtigt werden, dass das Fundensemble aufgrund des Randbeschlagfragmentes des Köchers aus dem Grab in der Seriation Péter Straubs in die Mitte von FA III eingereiht wurde. ${ }^{12}$ Andererseits ist kein Fundensemble im Karpatenbecken bekannt, das ein Schwert mit dreibogigem Aufhänger enthielte und in die Periode vor dem zweiten Viertel des 7. Jahrhunderts datiert werden könnte. Außerdem darf man nicht vergessen, dass auch dieses Grabensemble nicht vollständig ist, da es nicht im Ergebnis einer authentischen Ausgrabung, sondern als Geschenk in die

\footnotetext{
${ }^{105}$ BALOGH 2004.

${ }^{106}$ Diese gepidischen Funde sind nicht zu verwechseln mit den Gegenständen merowingischen Typs im 7. Jahrhundert, die in größerer Zahl und in ganz anderen Typen von awarenzeitlichen Fundensembles vorkommen.

${ }^{107}$ Nagy 1901, 316, Abb. 8-9; Somogyi 1987, 133.
}

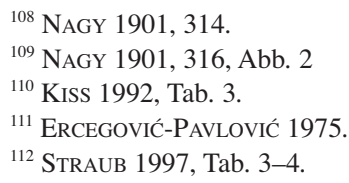


Museumssammlung kam. ${ }^{113}$ Demnach ist zwischen der Bestattung der Grabensembles von Manđelos und Szegvár mindestens die Zeit von zwei Generationen verstrichen.

Die Auflassung des Szegvárer Gräberfeldteils ist schwer exakt zu bestimmen. In dreien seiner Gräber kam je eine in Konstantinopel zwischen 616 und 625 auf jeweils anderem Prägestock entstandene Münze zum Vorschein, darunter ein Solidus sowie dessen goldene Imitation. ${ }^{114}$ Die Prägezeit der drei Münzen belegt terminus post quem die Belegung des Gräberfeldes bis zum Ende des ersten Drittels des 7. Jahrhunderts. Für die Periode nach dem durch die byzantinischen Münzen datierbaren Horizont sind in der Frauentracht Perlanhängerohrringe frühen Typs und die großen, hellgrünen Melonenkernperlen frühen Typs charkteristisch, die ins zweite Viertel und mittlere Drittel des 7. Jahrhunderts datiert werden können. ${ }^{115}$

Bei den Männergürteln bedeuten die Gürtel mit unvollständigen silbergepressten, runden Beschlägen mit Rand, Doppelschild- und Schild- bzw. Pseudoschnallen-Gürtelbeschlagbeständen die letzte Phase. Im Gräberfeld wird die allgemeine - in archäologischem Sinne verstandene - Verarmung bemerkbar, so dass diese Grabensembles chronologisch nicht einzuordnen sind. Für die späten Bestattungen sind sämtliche Brauchelemente typisch, die im Gräberfeld festgestellt wurden, mit Ausnahme der Nischengrabform.

Das Ende der Belegung des Gräberfeldes grenzen neben den obigen Feststellungen - wenn auch nur indirekt - Grab 924 und 925 ein. Die Orientierung der beiden, 40-45 cm voneinander parallel in einer Linie liegenden Schachtgräber - NW-SO, 332-152 - weicht erheblich, $90^{\circ}$, von den übrigen Gräbern des Feldes ab. In den rechteckigen Gräbern geringer Tiefe lagen die Skelettreste je eines 50-59-jährigen Mannes in gestreckter Rückenlage. Neben den in den Gräbern gefundenen einschneidigen Eisenmessern und Eisenschnallen verdient Erwähnung, dass während im einen Grab auf der linken Schulter der Skelettrest eines im Ganzen gebratenen Huhns ohne Kopf lag, das Grab des anderen Mannes im Bereich vom Kreuzbein bis zum Knie gestört/ausgeraubt war. Außen am oberen Ende des rechten Oberarmknochens lagen zwei schlecht erhaltene, rechteckige, gepresste silberne Zopfzierden in $3 \mathrm{~cm}$ dicker Erdschicht, mit der Vorderseite nach unten, zusammen mit der Füllmasse und dem Befestigungsbronzedraht.

Die Orientierung der beiden Gräber, ihre von den frühawarenzeitlichen Gräbern abweichenden Charakteristiken und die Tierbeigabe sowie die beiden silbernen Zopfspangen von Grab 925 zeigen eindeutig, dass im Gräberfeldgebiet in diesen zwei Gräbern mature Männer anderer Abstammung als die örtliche Gemeinschaft bestattet worden waren, sicherlich von ihren Familienmitgliedern.

Für die beiden Szegvárer Zopfspangen gibt es unter den aus dem Karpatenbecken publizierten Exemplaren $^{116}$ keine genaue Parallele. Das Auftreten der rechteckigen gepressten Zopfspangen in der Männertracht des Karpatenbeckens kann ins letzte Drittel des 7. Jahrhunderts datiert werden. ${ }^{117}$ Bei der Aufarbeitung der neueren Fundensembles wird ihre Belegungszeit in recht unterschiedliche, aber weit frühere Zeit als diese verlegt. ${ }^{118}$

Die Datierung der Grablege des in einer ausgeraubten Bestattung ohne andere Beigaben mit Datierungswert, allein gefundenen Silberblech-Zopfspangenpaares vor die 670er Jahre geschieht aus der Überlegung heraus, dass sich in den bisher freigelegten frühawarenzeitlichen Bestattungen keine Beigabe fand, die zuverlässig später als auf die Mitte des 7. Jahrhunderts datiert werden könnte. Zugleich befinden sich die beiden Bestattungen im Gräberfeld nicht in Superposition mit den frühawarenzeitlichen Gräbern, außerdem umgeben die frühawarenzeitlichen Gräber Grab 924 und 925 kreisförmig jenseits eines - selbst in Szegvárer Relation - großen, in allen Richtungen 1-3-9-12 m gräberfreien Gebietes. Demnach setzte sich die Belegung des Gräberfeldes nach der Bestattung der beiden Männer von für die Gemeinschaft fremder Herkunft noch fort und kann die Zeit seiner Auflassung in die Mitte des 7. Jahrhunderts gelegt werden.

\section{DIE ANTHROPOLOGISCHEN CHARAKTERISTIKEN DER BEVÖLKERUNG DES GRÄBERFELDES}

Obwohl die Untersuchung und Auswertung des anthropologischen Materials des Szegvárer Gräberfeldes abgeschlossen ist, kann von den anthropologischen Eigenarten der Gemeinschaft nur aufgrund von Vorausmittei-

${ }^{113}$ ERcEgOVIĆ-PAVLOVIĆ 1975, 107.

${ }^{114}$ SOMOGYI 1997a, 82-84.

${ }^{115}$ PÁsZTor 1995, 76-77; PÁsZTor 2008, 316-317; PÁsZ-

TOR 2012, 478; BALOGH-PÁSZTOR 2015, 622-623.

${ }^{116}$ ANDRÁSI 2000.
${ }^{117}$ BÓNA 1970, 250; ANDRÁSI 2000, 118.

${ }^{118}$ DAIM 1990, 156; SiMON-SZÉKELY 1991, 190; BALOGH 2013, 205 
lungen berichtet werden. ${ }^{119}$ Der Anteil der Kindersterblichkeit im Gräberfeld ist hoch (47 \%); er erreicht zusammen mit den Jugendlichen $60 \%$. Die Zahl der Frauen ist wesentlich höher (58 \%) als die der Männer (42\%).

Unter Berücksichtigung der einzelnen Lebensalter ist festzustellen, dass in der Altersgruppe Inf. I die Meisten im Alter von 1-2 bzw. 4-5 Jahren starben und in der Altersgruppe Inf. II im Alter von 7-8 Jahren. Die Verteilung der im Jugendalter Verstorbenen scheint gleichmäßig zu sein. Aufgrund der Altersgruppenverteilung der Männer gehören die Meisten zur maturen Altersgruppe, dieser folgt die adulte Gruppe. Bei den Frauen dagegen starben - anders als bei den Männern - mehr im jüngeren Erwachsenenalter.

Unter Beachtung der Ergebnisse der taxonomischen Analyse sind die Individuen der Szegvárer Serie mit dem größten Anteil Europo-Mongolide (59\%), ein geringerer Teil von ihnen weist europide (22\%) bzw. mongolide (18\%) Charakteristiken auf.

Der am allermeisten beachtenswerte Zug im anthropologischen Material des Gräberfeldes ist das sehr häufige Vorkommen der künstlich deformierten Schädel, das ausschließlich im Kreis der Frauen festzustellen ist.

Über die anthropologische Beschaffenheit der Bevölkerung im Gebiet östlich der Theiß kann heute noch sehr wenig gesagt werden. Neuere Angaben können außer von der Aufarbeitung des Szegvárer Materials noch von der Bewertung des Gräberfeldes von Makó-Mikócsa-halom ${ }^{120}$ erwartet werden. Das anthropologische Material der alten Ausgrabungen kann großenteils nicht untersucht werden, da es nicht oder nur fragmentarisch in Museumssammlungen kam. Sicher ist jedenfalls, dass sich die in Stollengräbern Bestatteten anthropologisch nicht von den übrigen Mitgliedern der Gemeinschaft unterscheiden. ${ }^{121}$

\section{HISTORISCHER AUSBLICK}

Die archäologisch erfassbaren und dokumentierbaren Erscheinungen der in den Szegvárer Gräbern festgestellten Bestattungssitten sind unter anderem Folgende: NO-SW-Orientierung, zusammengesetzte Grabformen (Nischen- und Stollengrab), deformierte Variante der partiellen Tierbestattung, räumliche Trennung von Verstorbenen und Tierbeigaben, Keramikgefäß und Lage der Lenden-, Kreuz- und Schwanzstücke vom Schaf neben dem Schädel. All diese sind in der großen Mehrheit der frühawarenzeitlichen Bestattungen östlich der Theiß allgemein üblich. Diese Bestattungssitten sind jede gesondert und auch gemeinsam signifikante Erscheinungen im damaligen Karpatenbecken. Das lässt die Anwesenheit einer Bevölkerung mit anderer Tradition als die der übrigen Völker des Awarenreiches wahrscheinlich werden.

Die Kette der nur für diese Gemeinschaften typischen Bestattungssitten bietet ausreichenden Grund für die Annahme, dass die sich hier niedergelassene Volksgruppe in ihrer Herkunft und auch kulturellen Bindung eine geschlossene Gemeinschaft war. ${ }^{122}$ Sie bildete - aufgrund des aus der osteuropäischen Steppe bekannten archäologischen Fundmaterials und der Bestattungssitten - die osteuropäische nomadische Komponente des Awarentums im Karpatenbecken. ${ }^{123}$

Eine akzeptierte Meinung ist, dass mit den Awaren zusammen auch Volksgruppen der osteuropäischen Steppe an der Besetzung des Karpatenbeckens in den Jahren 567-568 teilgenommen haben. ${ }^{124}$ Die ethnische Identifizierung dieser Bevölkerung ist seit Dezső Csallánys Artikel von 1934 bis heute umstritten. ${ }^{125}$ Der Grund für die unterschiedlichen Meinungen ist, dass keine schriftliche Quelle über jene erhalten blieb, die das hier behandelte Gebiet am Ende des 6. Jahrhunderts besetzt haben. Aber auch wenn es keine eindeutige Angabe über sie gibt, bieten doch einzelne Bemerkungen damaliger Quellen die Möglichkeit, gewisse Folgerungen zu ziehen.

Der kaum drei Jahrzehnte dauernden und fast ständig in kriegerischer Atmosphäre verbrachten Nachbarschaft von Langobarden und Gepiden machte das Erscheinen der Awaren damit ein Ende, dass Khagan Bajan und die langobardischen Gesandten nach langer ,Schlichtung“ übereinkamen, dass die Awaren an der Seite der Langobarden am Kampf gegen die Gepiden teilnehmen, ,,jedoch nur unter der Bedingung, daß sie ihm unverzüglich ein

2000.

\footnotetext{
${ }^{119}$ FÓthI-LŐRINCZY 2000; FóthI-LÖRINCZY-MARCSIK

${ }^{124}$ Beispielsweise BÁLINT 1978, 196-199; BÓNA 1984, 325327; SOMOGYI 1987, 148-149. Kritischer ist BáLINT 1992, 399-400.

${ }^{125}$ Beispielsweise CSALLÁNY 1934; BóNA 1971, 301-303;

${ }^{120}$ SOMOGYI 2014, 198; BALOGH 2016.

${ }^{121}$ MARCSIK-SZALAI 1995.

${ }^{122}$ LÖRINCZY 1998, 354

${ }^{123}$ SOMOGYI 1991, 115. 
Zehntel des gesamten Viehbestandes der Langobarden überließen; für den Fall eines Sieges beanspruchte er die Hälfte der Beute und das ganze Gepidenland“. ${ }^{126}$

Auf die Frage, zu wem und wohin der in der Vereinbarung genannte Viehbestand gelangt sein möge, muss auf die der Antwort zugrunde liegenden archäozoologischen Untersuchungen und ihre Ergebnisse wahrscheinlich noch ein oder zwei Jahrzehnte gewartet werden. Ein Versuch, die Beute zu identifizieren, die nach dem schicksalsentscheidenden Krieg - unmittelbar nach der siegreichen Schlacht gewonnen bzw. als Tribut von den unterlegenen Gepiden - errungen worden war, wurde noch nicht unternommen. Dagegen haben sich in einem großen - zentralen - Teil des Quartiergebietes der besiegten Gepiden in der Tiefebene, im Gebiet zwischen Körös, Theiß und Aranka, vor allem im Streifen entlang von Theiß und Maros, nicht Bajans Awaren niedergelassen, sondern Gemeinschaften, die sie aus der osteuropäischen Steppe mitgerissen hatten. ${ }^{127}$ Diese Tatsache lässt die Möglichkeit zu, dass - obwohl Khagan Bajan ein Bündnis geschlossen hatte - das am langobardisch-gepidischen Krieg teilnehmende Militärkontingent von der nach dem Krieg das Gebiet besetzenden Bevölkerung gestellt worden war und ihre Mitglieder als Sieger an den Kämpfen teilgenommen hatten. Dafür spricht auch die Überlegung, dass die Wahrscheinlichkeit gering ist, dass das Gebiet, um das das awarische Heer gekämpft hatte, einem unterworfenen, angeschlossenen Volk überlassen worden sei.

In der osteuropäischen Steppe war bei den Kutriguren westlich des Don der Südteil des Karpatenbeckens nicht mehr unbekannt. Die zweijährige Waffenruhe vor der langobardisch-gepidischen Entscheidungsschlacht hatten die Gepiden dazu genutzt, die Kutriguren zu Hilfe zu rufen, die allerdings zu früh kamen, weswegen die gepidische Führung das Kutrigurenheer zur Entschädigung in das den Gepiden gegenüberliegende byzantinische Gebiet umlenkte. ${ }^{128}$

Khagan Bajan sandte, als er 568 das Karpatenbecken besetzen wollte, nach der ersten erfolglosen Einnahme Sirmiums zehntausend Kutriguren zur Verwüstung Dalmatiens über die Save. ${ }^{129}$ Das bedeutet also, dass die kutrigurischen Militäreinheiten damals innerhalb des Karpatenbeckens gewesen sein müssen, denn nur dann war es ihnen möglich, die Save zu überschreiten.

Aufgrund der obigen Fakten geben die byzantinischen Quellen von den in der Steppe lebenden Nomaden, ${ }^{130}$ die sich den nach Westen ziehenden Awaren - freiwillig oder gezwungenermaßen - angeschlossen hatten, bezüglich des Karpatenbeckens nur über die Kutriguren eine bewertbare Information. ${ }^{131}$ Zugleich sprechen die Quellen nach der awarischen Wanderung nicht von Kutriguren oder Utiguren östlich vom Karpatenbecken. ${ }^{132}$

Aufgrund der frühawarenzeitlichen Bestattungssitten und eines heute noch sehr schmalen Fundhorizontes des archäologischen Nachlasses aus den Gräbern sowie der vereinzelten Nachrichten byzantinischer Quellen kann angenommen werden, dass das Gebiet östlich der Theiß von den in den damaligen Quellen Kutriguren genannten bzw. der von ihnen geführten Steppenbevölkerung besetzt worden ist. Die ethnische Zusammensetzung dieser Bevölkerung kann heute archäologisch noch nicht bestimmt werden. Auf die Schwierigkeiten, sie zu separieren und zu identifizieren, weist die folgende Quelle sehr plastisch hin.

Gegen die 559 byzantinische Gebiete angreifenden Kutriguren forderte Kaiser Justinianus die Utiguren zum Krieg auf, die dem Kaiser - wie Menander Protektor schreibt - unter anderem Folgendes antworteten: „Es ist weder gottgefällig noch auch überhaupt schicklich, Stammesgenossen ganz und gar auszurotten. Sie sind mit uns nicht nur sprachverwandt, Landsleute und durch gleiche Tracht und Lebensweise verbunden, sondern sogar blutsverwandt, wenn sie auch unter anderen Fürsten stehen." ${ }^{\text {133 }}$ Diese Beschreibung deutet die Schwierigkeit an, dass es schwer sein wird, aufgrund ihrer gegenständlichen Hinterlassenschaft die Utiguren und Kutriguren wegen ihrer ähnlichen Tracht und Lebensweise zu unterscheiden. Andererseits ist auch die Möglichkeit nicht auszuschließen, dass aufgrund des in der osteuropäischen Steppe und im Karpatenbecken ständig wachsenden archäologischen Fundmaterials, der gemeinsamen Auswertung von Bestattungssitten und Totenkult sowie der verschiedenen natur-

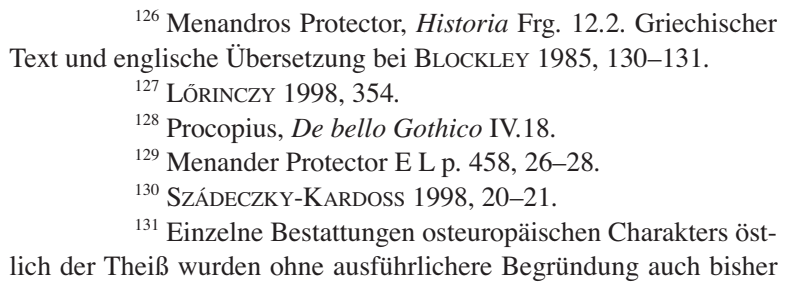

${ }^{126}$ Menandros Protector, Historia Frg. 12.2. Griechischer Text und englische Übersetzung bei BLOCKLEY 1985, 130-131.

${ }^{127}$ LÓRINCZY 1998, 354.

${ }^{128}$ Procopius, De bello Gothico IV.18.

${ }^{129}$ Menander Protector E L p. 458, 26-28.

${ }^{130}$ SZÁdECZKY-KARDOSS 1998, 20-21.

${ }^{131}$ Einzelne Bestattungen osteuropäischen Charakters östlich der Theiß wurden ohne ausführlichere Begründung auch bisher

schon von mehreren Forschern den Kutriguren zugeschrieben; z. B. CSAllány 1934, 212; Somogyi 1987, 147; BónA 1990, 115; KÜRTI 1996, 130-131.

${ }^{132}$ Komar 2004, 194.

${ }_{133}$ Menander Protector, Historia Frg. 2. Griechischer Text und englische Übersetzung bei BLOCKLEY 1985, 42-45. 
wissenschaftlichen - mtDNS- und Strontium-Isotopen- - Untersuchungen beantwortet werden kann, aus welchen Gemeinschaften östlich der Theiß im 6. Jahrhundert die Mitglieder der ersten Generation östlich des Don geboren wurden und aus welchen in westlich von ihnen gelegenen Gebieten.

\section{DANKSAGUNG}

Die komplexe Bearbeitung des Gräberfeldes von Szegvár aus dem 6.-7. Jahrhundert ist abgeschlossen und das Werk für die Drucklegung bereit. Herzlich danke ich den an der Bearbeitung des Gräberfeldes beteiligten Kollegen, Archäologen, Anthropologen, Archäozoologen und den Spezialisten anderer Grundwissenschaften - Gergely Csiky, Aranka Csősz, Antónia Marcsik, Balázs Gusztáv Mende, Adrien Pásztor, Zsuzsanna Siklósi, Peter Stadler, Tivadar Vida und István Vörös - für ihre lange und ausdauernde Arbeit. Den Aufsatz haben Péter Somogyi und Péter Tomka lektoriert. Für ihre nützlichen und debattenanregenden, wertvollen Bemerkungen möchte ich ihnen Dank sagen. ${ }^{134}$

\section{QUELLEN}

Menandros Protector: Historiae. In: R. C. Blockley (ed., text and transl.): The History of Menander the Guardsman. Liverpool 1985. Procopius: De bello Gothico I-IV. In: O. Veh (Hrsg.): Gotenkriege. Prokop Werke. 2. München 1966.

\section{LITERATUR}

ANDRÁSi 2000

BÁLINT 1978

BÁLINT 1992

BÁLINT 1995

BALOGH 2004

BALOGH 2013

BALOGH 2016

BALOGH-PÁSZTOR 2015

BANNER 1927
BENDE 2000

= J. ANDRÁSI: Avar kori varkocsszorítók (Awarenzeitliche Zopfspangen). ArchÉrt 123-124 (19961997 [2000]) 85-123.

= Cs. BÁLINT: Vestiges archeologiques de l'epoque tardive des Sassanides et leurs relations avec les peuples des steppes. ActaArchHung 30 (1978) 174-212.

= Cs. BÁLint: Kontakte zwischen Iran, Byzanz und der Steppe. Das Grab von Üč-Tepe (Sow. Azerbajdžan) und die beschlagverzierten Gürtel im 6. und 7. Jahrhundert. In: Awarenforschungen I. Hrsg.: F. Daim. Wien 1992, 309-496.

= Cs. BÁLINT: Kelet, a korai avarok és Bizánc kapcsolatai. Régészeti tanulmányok [Die Beziehungen von Osten, den frühen Awaren und Byzanz. Archäologische Studien]. Magyar őstörténeti könyvtár. Szeged 1995.

= Cs. BALOGH: Martinovka-típusú övgarnitúra Kecelről. A Kárpát-medencei maszkos veretek tipokronológiája (Gürtelgarnitur des Typs Martinovka von Kecel. Die Typochronologie der Maskenbeschläge des Karpatenbeckens). MFMÉ-StudArch 10 (2004) 241-304.

= Cs. BALOGH: A Duna-Tisza köze avar kori betelepülésének problémái [Probleme der Ansiedlung des Donau-Theiß-Zwischenstromlandes in der Awarenzeit]. ELTE PhD-dolgozat. [Manuskript.] Budapest 2013.

= Cs. BAlogh: Karpat Havzası'nda Bir Avar Yay Ustasının Mezar Kalıntıları. Eski Türklerde Bileşik (Kompozit) Yay Yapımına İlişkin Arkeolojik Bulgular (The grave of an Avar bowyer in the Carpathian Basin). Art-Sanat Dergisi 6 (2016) 109-120.

= Cs. BALOGH-A. PÁsZTOR: Az avar kori nagy gyöngycsüngős fülbevalók (Large bead-pendant earrings from the Avar period). In: Hadak útján 24. A népvándorláskor fiatal kutatóinak XXIV. konferenciája, Esztergom 2014. I. Hrsg.: Cs. Balogh, B. Major. Studia ad Archaeologiam Pazmaniensia - Magyar Ôstörténeti Témacsoport kiadványok 3.1. Budapest-Esztergom 2015, 581-648.

= J. BANNER: Népvándorláskori sírok Nagykamaráson (Gräber aus der Völkerwanderungszeit bei Nagykamarás). Dolg 3 (1927) 141-159.

= L. BENDE: Fülkesírok a pitvarosi avar kori temetőben. Adatok a fülkés és lószerszámos temetkezések kronológiájához (Stollengräber im awarenzeitlichen Gräberfeld von Pitvaros. Angaben zur Chronologie der Stollengräber und Bestattungen mit Pferdegeschirr). In: Hadak útján 10. A népván-

${ }^{134}$ Die Illustrationszeichnungen fertigten Zsuzsanna Czabarka, die Graphikerin Margit Koncz und die Restauratorin Ágnes
Szőke, die Tabellen Edit Ambrus an. Die Grabfotos sind Aufnahmen des Verfassers. 
BENDE 2003a

BENDE 2003b

BENDE 2006

\section{BENDE-LŐRINCZY 1997}

BÓNA 1970

BÓNA 1971

BÓNA 1979

BÓNA 1980

BÓNA 1981

BÓNA 1984

BÓNA 1986

BÓNA 1990

CSAllány 1934

CSALlÁNy 1939

CsAlláNy 1960

DAIM 1987

DAIM 1990

DÖRNER 1961

ERCEGOVIĆ-PAVLOVIĆ 1975

FÓTHI-LŐRINCZY 2000

FÓTHI-LŐRINCZY-MARCSIK 2000

GARAM 1992

GARAM 1995

GARAM 2005

HERENDI 2012

ISTVÁNOVITS-LŐRINCZY-PINTYE 2005 dorláskor fiatal kutatóinak X. konferenciája, Domaszék 1999. Hrsg.: L. Bende, G. Lőrinczy, Cs. Szalontai. Szeged 2000, 241-279.

= L. BENDE: Temetkezési szokások a székkutas-kápolnadülői avar temetőben (Bestattungssitten im awarenzeitlichen Gräberfeld von Székkutas-Kápolnadülő). In: K. B. Nagy: A székkutaskápolnadűlői avar temető. MFMÉ MonArch 1. Szeged 2003, 305-330.

= L. BENDE: Avar temető Örménykúton (Ein awarisches Gräberfeld in Örménykút). MFMÉ-StudArch 9 (2003) 189-210.

= L. BENDE: Bestattungssitten in der zweiten Hälfte der Awarenzeit in der durch die Flüsse Körös, Tisza und Maros umgebenen Landschaft (Burial customs in the second half of the Avar Age in the area bordered by the Körös, Tisza and Maros rivers). Arrabona 44/1 (2006) 87-110.

= L. BENDE-G. LŐRINCZY: A szegvár-oromdülői 10-11. századi temető (Das Gräberfeld von SzegvárOromdülő aus dem 10. bis 11. Jahrhundert). MFMÉ-StudArch 3 (1997) 201-286.

= I. BóNA: Avar lovassír Iváncsáról (Grave of an avar horseman at Iváncsa). ArchÉrt 97 (1970) 243-263.

= I. BÓNA: Ein Vierteljahrhundert Völkerwanderungszeitforschung in Ungarn (1945-1969). Acta ArchHung 23 (1971) 265-336.

= I. BÓNA: A szegvár-sápoldali lovassír. Adatok a korai avar temetkezési szokásokhoz (Das Reitergrab von Szegvár-Sápoldal. Beiträge zu den frühawarischen Bestattungssitten). ArchÉrt 106 (1979) 3-32.

= I. BÓNA: Studien zum frühawarischen Reitergrab von Szegvár. ActaArchHung 32 (1980) 31-95.

= I. BÓNA: Das erste Auftreten der Bulgaren im Karpatenbecken. ActaArch Turco-Hungarica 5 (1981) 79-112.

= I. BóNA: A népvándorlás kor és a korai középkor története Magyarországon [Die Geschichte der Völkerwanderungszeit und des frühen Mittelalters in Ungarn]. In: Magyarország története. I.: Előzmények és magyar történet 1242-ig. Hrsg.: A. Bartha. Budapest 1984, 265-374.

= I. BónA: Szabolcs-Szatmár megye régészeti emlékei 1. [Archäologische Denkmäler im Komitat Szabolcs-Szatmár 1]. In: Szabolcs-Szatmár megye müemlékei 1. Hrsg.: G. Entz. Magyarország müemléki topográfiája 10. Budapest 1986, 15-91.

= I. BÓNA: Beiträge zum asiatischen Ursprung der awarenzeitlichen partiellen Pferdebestattungen. WMMÉ 15 (1990) 113-123.

= D. CsALlÁNY: A Szentes-lapistói népvándorláskori sírlelet (Der Grabfund von Szentes-Lapistó aus der Völkerwanderungszeit). Dolg 9-10 (1933-34 [1934]) 206-214.

= D. CSALLÁNY: A Szentes-derekegyházi népvándorláskori sírlelet (Der völkerwanderungszeitliche Grabfund von Szentes-Derekegyháza). FolArch 1-2 (1939) 116-120.

= D. CsallánY: Szabolcs-Szatmár megye avar leletei (Awarische Funde des Komitats Szabolcs-Szatmár). JAMÉ 1 (1958 [1960]), 31-85.

= F. DAIM: Das awarische Gräberfeld von Leobersdorf, Niederösterreich. Studien zur Archäologie der Awaren 3/1. Veröffentlichungen der Kommission für Frühmittelalterforschung 10. Wien 1987.

= F. DAIM: Das Gräberfeld von Zilingtal. Die Grabungen 1985-89. WMMÉ 15 (1990) 155-161.

= E. DöRnER: Mormînt din epoca avară la Sînpetru-German (Tombe de l'époque avare découverte à Sînpetru-German). SCIV 11 (1960) 423-434.

= S. ERCEGOviĆ-PAVlović: Avarski konjanički grob iz Manđelosa [An Avarian Equesttian Grave from Manđelos]. Starinar 24-25 (1973-1974 [1975]) 107-114.

= E. FÓTHI-G. LŐRINCZY: Torzított koponyájú népesség a Szegvár-Oromdűlő kora avar kori temetőből [Die Bevölkerung mit deformiertem Schädel aus dem frühawarenzeitlichen Gräberfeld von SzegvárOromdülő]. AnthrK 41 (2000) 23-39.

= E. FÓTHI-G. LŐRINCZY-A. MARCSIK: Régészeti és antropológiai kapcsolat az eurázsiai steppe és egy kora avar kori, Kárpát-medencei népesség között. Előzetes közlemény (Archaeological and anthropological relationship between the Eurasian steppe and an early Avar population of the Carpathian Basin). MFMÉ-StudArch 6 (2000) 191-198.

= É. GARAM: Die münzdatierten Gräber der Awarenzeit. In: Awarenforschungen 1. Hrsg.: F. Daim. ArchA Monographien 1-2. Studien zur Archäologie der Awaren 4. Wien 1992, 135-250.

= É. GARAM: Das awarenzeitliche Gräberfeld von Tiszafüred. Cemeteries of the Avar Period in Hungary 3. Budapest 1995.

= É. GARAM: Avar kori női fejdíszek [Der Kopfschmuck der Frauen in der Awarenzeit]. ZalaiMúz 14 (2005) 169-181.

= O. HERENDI: Avar kori női sír Hódmezővásárhely-Kopáncson (Csongrád megye) (Avar Age female grave at Hódmezővásárhely-Kopáncs, Csongrád County). In: Évkönyv és Jelentés a Kulturális Örökségvédelmi Szakszolgálat 2009. évi feltárásairól - Field Service for Cultural Heritage 2009 Yearbook and review of archaeological investigations. Ed.: J. Kvassay. Budapest 2012, 351-362.

= E. IsTVÁNOviTS-G. LŐRINCZY-G. PINTYE: A szegvár-oromdűlői császárkori telep (Die frühkaiserzeitliche Siedlung von Szegvár-Oromdűlő). MFMÉ-StudArch 11 (2005) 51-114. 
KISS 1992

KIss 1996

KOMAR 2004

KOREK 1942

KovRIG 1963

KÜRTI 1996

KÜRTI 2002

KÜRTI 2003

LANGÓ-TÜRK 2004

LÖRINCZY 1992a

LŐRINCZY 1992b

LŐRINCZY 1994

LŐRINCZY 1995

LÖRINCZY 1996

LŐRINCZY 1998

LŐRINCZY 2001

LŐRINCZY-RÁCZ 2014

LŐRINCZY-STRAUB 2004

LŐRINCZY-STRAUB 2005

LŐRINCZY-STRAUB 2006

LŐRINCZY-STRAUB 2012

LŐRINCZY-SZALONTAI 1996
= A. KIss: Zur Zeitstellung des „,münzdatierten“ awarischen Fürstengrabes von Kunágota (A kunágotai éremmel „keltezett” avar kori fejedelmi sír időrendjéhez). JPMÉ 36 (1991 [1992]) 67-84.

= A. KIss: Das awarenzeitlich gepidische Gräberfeld von Kölked-Feketekapu A. Monographien zur Frühgeschichte und Mittelalterarchäologie 2. Studien zur Archäologie der Awaren 5. Innsbruck 1996.

= A. B. Komar: Кутригуры и утигуры в Северном Причерноморье [Kutriguren und Utiguren an der nördlichen Küste des Schwarzen Meeres]. In: Сугдейский сборник. Ред.: В. В. Майко. КиевСудак 2004, 169-200.

= J. KoREK: A Szárazér-dűlői avar lovassír (Awaren-Reitergrab in Szárazér-dűlő). Dolg 18 (1942) $156-159$.

= I. KovRIG: Das awarenzeitliche Gräberfeld von Alattyán. ArchHung 40. Budapest 1963.

= B. KÜRTI: Régészeti párhuzamok a Kárpát-medencei avar kori fülkesírok (Stollengräber) keleti eredetéhez [Archäologische Parallele zur östlichen Herkunft der awarenzeitlichen Stollengräber]. Tisicum 1996, 125-135.

= B. KÜRTI: Deszk - G; Kiszombor - M, Rónai I. birtoka. In: Archäologische Denkmäler der Awarenzeit in Mitteleuropa. Hrsg.: J. Szentpéteri. VAH 13. Budapest 2002, 109-110, 203.

= B. KÜRTI: Avar lovas - magyar lovas Szöregen és Eperjesen (Awarischer Reiter - ungarischer Reiter in Szöreg und Eperjes). MFMÉ-StudArch 9 (2003) 229-242.

= P. LANGÓ-A. TÜRK: Móra nyomában - Előzetes beszámoló a Kiszombor határában 2003-ban végzett honfoglalás kori lelőhelyek hitelesítő feltárásairól [Ferenc Móra auf der Spur - Vorläufiger Bericht über die Ausgrabungen der landnahmezeitlichen Fundorte in der Gemarkung von Kiszombor im Jahre 2003]. MKCsM 2003 (2004) 203-214.

= G. LÖRINCZY: Vorläufiger Bericht über die Freilegung des Gräberfeldes aus dem 6.-7. Jahrhundert in Szegvár-Oromdülö. Weitere Daten zur Interpretierung und Bewertung der partiellen Tierbestattungen in der frühen Awarenzeit. CommArchHung 1993, 81-124.

= G. LŐRINCZY: Megjegyzések a kora avar kori temetkezési szokásokhoz. A tájolás [Anmerkungen zu den frühawarenzeitlichen Bestattungssitten. Die Orientierung]. JAMÉ 30-32 (1987-1989 [1992]) $155-171$.

= G. LőRINCZY: Megjegyzések a kora avar kori temetkezési szokásokhoz. A fülkesíros temetkezés (Bemerkungen zu den frühawarenzeitlichen Bestattungssitten. Die Stollengräber). In: A kőkortól a középkorig. Tanulmányok Trogmayer Ottó 60. születésnapjára / Von der Steinzeit bis zum Mittelalter. Studien zum 60. Geburtstag von Ottó Trogmayer. Hrsg.: G. Lőrinczy. Szeged 1994, 311-335.

= G. LŐRINCZY: Fülkesírok a szegvár-oromdülői kora avar kori temetőből. Néhány megjegyzés a fülkesíros temetkezések változatairól, kronológiájáról és területi elhelyezkedéséről (Stollengräber im frühawarenzeitlichen Gräberfeld von Szegvár-Oromdülő. Beiträge zu den Varianten, zur Chronologie und territorialen Lage der Stollengräber). MFMÉ-StudArch 1 (1995) 399-416.

= G. LőRINCZY: Kora avar kori sír Szentes-Borbásföldről (Ein frühawarenzeitliches Grab in SzentesBorbásföld). MFMÉ-StudArch 2 (1996) 177-190.

= G. LỎRINCZY: Kelet-európai steppei népesség a 6-7. századi Kárpát-medencében. Régészeti adatok a Tiszántúl kora avar kori betelepüléséhez (Osteuropäische Steppenbevölkerung im 6. und 7. Jahrhundert im Karpatenbecken. Archäologische Beiträge zur frühawarenzeitlichen Einsiedlung des Gebietes jenseits der Theiß). MFMÉ-StudArch 4 (1998) 343-372.

= G. LŐRINCZY: Szabolcs-Szatmár-Bereg megye avar sírleletei I. (Avarian grave finds from SzabolcsSzatmár-Bereg County). JAMÉ 43 (2001) 185-196.

= G. LöRINCZY-Zs. RÁCZ: Szabolcs-Szatmár-Bereg megye avar sírleletei II. Tiszavasvári-Kashalomdülő kora avar kori temetkezései (Avarian finds from Szabolcs-Szatmár-Bereg County. II: Early Avarian graves from Tiszavasvári-Kashalom-dűlő). JAMÉ 56 (2014) 141-217.

= G. LÖRINCZY-P. STRAUB: Újabb adatok az avar kori szürőkanalak értékeléséhez II. (Neue Angaben zur Bewertung der awarenzeitlichen Sieblöffel II). MFMÉ-StudArch 10 (2004) 305-337.

= G. LÖRINCZY-P. STRAUB: Újabb adatok az avar kori szürőkanalak értékeléséhez III. (Neue Angaben zur Bewertung der awarenzeitlichen Sieblöffel III). MFMÉ-StudArch 11 (2005) 127-145.

= G. LỏRINCZY-P. STRAUB: Az avar kori padmalyos temetkezésekről. Szempontok a Kárpát-medencei padmalyos temetkezések értékeléséhez (Über die awarenzeitlichen Nischengräber. Angaben zur Bewertung der Nischengräber des Karpatenbeckens). Arrabona 44/1 (2006) 279-316.

= G. LŐRINCZY-P. STRAUB: Néhány megjegyzés a Hajdúdorog-Városkert úti 1. sírról. Adatok az avar kori sisakokhoz (Grave 1 from Hajdúdorog-Városkert road. Helmets of the Avar period). In: Thesaurus Avarorum. Régészeti tanulmányok Garam Éva tiszteletére / Thesaurus Avarorum. Archaeological Studies in Honour of Éva Garam. Ed.: T. Vida. Budapest 2012, 395-405.

= G. LŐRINCZY-Cs. SZALONTAI: Újabb régészeti adatok Csongrád megye területének 6-11. századi településtörténetéhez II. (Neuere archäologische Angaben zur Siedlungsgeschichte des Komitates Csongrád vom 6. bis 11. Jahrhundert II). MFMÉ-StudArch 2 (1996) 269-298. 
MARCSIK-SZALAi 1995

NAGY 1901

B. NAGY 2003

PÁSZTOR 1995

PÁsZTOR 2008

PÁSZTOR 2012

RÁCZ 2014

RÁCZ-SZENTHE 2010

RANISAVLJEV 2007

RóZSA 2002

RÓZSA-VÖRÖS 2004

SIKLÓSI 2014

SIMON-SZÉKELY 1991

Somogyi 1987

SOMOGYI 1991

Somogyi 1997a

SOMOGYI 1997b

SOMOGYI 2008

SOMOGYI 2009

Somogyi 2014

STRAUB 1997

SZÁDECZKY-KARDOSS 1998

TOMKA 1975

TOMKA 1995

TOMKA 2003

TOMKA 2008
= A. MARCSIK-F. SzALAI: Néhány megjegyzés a fülkés sírokba eltemetett egyének embertani arculatáról (Einige Bemerkungen über den anthropologischen Charakter der in den Stollengräbern bestatteten Individuen). MFMÉ-StudArch 1 (1995) 453-458.

= G. NAGY: Sírleletek a régibb középkorból. III: Némedi, Tolna megye [Grabfunde aus dem älteren Mittelalter. III. : Némedi, Komitat Tolna]. ArchÉrt 21 (1901) 314-318.

= K. B. NAGY: A székkutas-kápolnadülői avar temető [Das awarische Gräberfeld von SzékkutasKápolnadülö]. In: K. B. Nagy: A székkutas-kápolnadülői avar temető. MFMÉ MonArch 1. Szeged 2003.

= A. PÁszTOR: A kora és középavar kori gyöngyök és a bizánci éremleletes sírok kronológiai kapcsolata (Die chronologische Beziehung der Perlen und byzantinische Münzen führenden früh- und mittelawarenzeitlichen Gräber). SMK 11 (1995) 69-92.

= A. PÁszTOR: Ergebnisse der typochronologischen Untersuchung awarenzeitlicher Perlenfunde in Ungarn - Perlentracht in der Früh- und Mittelawarenzeit. Antaeus 29-30 (2008) 307-324.

= A. PÁszTor: Lesencetomaj-Piroskereszt avar kori temetö 39. sírjának gyöngysora (Die Perlenkette aus Grab 39 des awarenzeitlichen Gräberfeldes von Lesencetomaj-Piroskereszt). In: Thesaurus Avarorum. Régészeti tanulmányok Garam Éva tiszteletére / Thesaurus Avarorum. Archaeological Studies in Honour of Éva Garam. Ed.: T. Vida. Budapest 2012, 477-488.

= Zs. RÁCZ: Die Goldschmiedegräber der Awarenzeit. Monographien des Römisch-Germanischen Zentralmuseums 116. Mainz 2014.

= Zs. RÁCZ-G. SzENTHE: Avar temetö Hajdúnánás határában (Awarisches Gräberfeld in der Gemarkung von Hajdúnánás). ComArchHung 2009 [2010] 309-335.

= А. РАниСАвљЕв: Раносредњовековна некропола код Мокрина (Early Medieval Necropolis near Mokrin). Српско археолошко друштво. Повремена издања 4. Београд 2007.

= Z. RózSA: Kora avar sír Tótkomlósról (Ein frühawarisches Grab von Tótkomlós). MFMÉ-StudArch 8 (2002) 341-344.

$=$ Z. RÓZSA-I. VöRÖs: Kora avar sír Gyulán (Early Avar grave in Gyula). In: RégKut 2002. Budapest 2004, 35-42.

= Zs. SIKLósı: A Tiszavasvári-Kashalom-dűlőben és Hajdúnánás-Fürj-halom-járáson feltárt avar sírok radiokarbon keltezése (Radiocarbon dating of Avar graves excavated in Tiszavasvári-Kashalomdűlő and Hajdúnánás-Fürj-halom-járás). JAMÉ 56 (2014) 229-236.

= L. SimON-L. SzÉKelY: Korai avar leletek Dabas (Gyón)-Paphegyről (Frühawarenzeitliche Funde von Dabas (Gyón)-Paphegy). MFMÉ 1984-1985/2 (1991) 187-203.

= P. Somogyı: Typologie, Chronologie und Herkunft der Maskenbeschläge. Zu den archäologischen Hinterlassenschaften osteuropäischer Reiterhirten aus der Pontischen Steppe im 6. Jahrhundert ArchA 71 (1987) 121-154.

= P. SOMOGYI: Lábbeliveretek a délorosz sztyeppéről (Beschläge der Fußbekleidung aus der südrussischen Steppe). MFMÉ 1984-1985/2 (1991) 105-125.

= P. SomogyI: Byzantinische Fundmünzen der Awarenzeit. Monographien zur Frühgeschichte und Mittelalterarchäologie 5. Innsbruck 1997.

= P. SomogYI: Drei frühawarenzeitliche Bestattungen aus der Fundstelle Nr. 264 von Gyoma (Három kora avar kori sír a Gyoma 264. sz. lelőhelyről). MFMÉ-StudArch 3 (1997) 97-116.

= P. SOMOGYI: Neue Überlegungen über den Zustrom byzantinischer Münzen ins Awarenland. Numismatischer Kommentar zu Csanád Bálints Betrachtungen zum Beginn der Mittelawarenzeit. Antaeus 29-30 (2008) 347-393.

= P. Somogyi: Byzantinische Fundmünzen der Awarenzeit. Eine Bestandsaufnahme 1998-2007. AAC 42-43 (2009) 231-299.

= P. Somogyi: Byzantinische Fundmünzen der Awarenzeit in ihrem europäischen Umfeld. DissPann IV:2. Budapest 2014.

$=$ P. STRAUB: Avar kori tegezdíszitő csontlemezek. Motívumtipológia és kronológia (Awarenzeitliche Beinplatten als Verzierungen von Köchern. Typologie der Motive und Chronologie). MFMÉ-StudArch 3 (1997) 117-151.

= S. SzÁdECZKY-KARDoss: Az avar történelem forrásai [Quellen der Geschichte der Awaren]. Budapest 1998 .

= P. ToMKA: Adatok a Kisalföld avar kori népességének temetkezési szokásaihoz. II. Tájolás (Beiträge zu den Bestattungsarten der Bevölkerung von Kisalföld in der Awarenzeit. II. Orientierung). Arrabona 17 (1975) 5-90.

= P. Tomka: Il costume. In: Gli avari. Un popolo d'Europa. A cura di C. G. Menis. Udine 1995, 81-92.

$=$ P. TomKA: Az avar kori temetkezési szokások kutatásának újabb eredményei. Kettős és többes temetkezések (The latest results of the research focussing on the funeral customs in the Avar Age. Double and multiple burials). Arrabona 41 (2003) 11-56.

= P. TomKA: Die Lehre der Bestattungssitten. Antaeus 29-30 (2008) 233-264. 
VIDA 2003

VÖRÖS 2002

ZDROBA-BARBU 1976
$=\mathrm{T}$. VIDA: The Early and Middle Avar Period (568 - turn of the 7th-8th centuries). In: Hungarian Archaeology at the Turn of the Millennium. Ed.: Zs. Visy, M. Nagy, Zs. B. Kiss. Budapest 2003, 302-307.

= I. VÖRÖs: Áldozatiállat-maradványok a tótkomlósi avar kori sírban (Reste von Opfertieren im awarenzeitlichen Grab von Tótkomlós). MFMÉ-StudArch 8 (2002) 345-350.

= M. ZDROBA-M. BARBU: Săpăturile arheologice de la Felnac şi Vladimirescu [Archäologische Grabungen im Gebiet von Felnac und Vladimirescu]. Ziridava 6 (1976) 47-56. 